NBER WORKING PAPER SERIES

\title{
CLASS SIZE AND SORTING IN MARKET EQUILIBRIUM: THEORY AND EVIDENCE
}

\author{
Miguel Urquiola \\ Eric Verhoogen \\ Working Paper 13303 \\ http://www.nber.org/papers/w13303 \\ NATIONAL BUREAU OF ECONOMIC RESEARCH \\ 1050 Massachusetts Avenue \\ Cambridge, MA 02138 \\ August 2007
}

We thank Kensuke Teshima for excellent research assistance. For useful comments we thank (without implicating) Josh Angrist, Jere Behrman, David Card, Ken Chay, Pierre-Andre Chiappori, Gregory Elacqua, Helios Herrera, Kate Ho, Larry Katz, David Lee, Robert Moffitt, Richard Romano, Bernard Salanie, and many seminar participants. We especially thank Patrick McEwan, who was involved in the early stages of the project. The views expressed herein are those of the author(s) and do not necessarily reflect the views of the National Bureau of Economic Research.

(C) 2007 by Miguel Urquiola and Eric Verhoogen. All rights reserved. Short sections of text, not to exceed two paragraphs, may be quoted without explicit permission provided that full credit, including (C) notice, is given to the source. 
Class Size and Sorting in Market Equilibrium: Theory and Evidence

Miguel Urquiola and Eric Verhoogen

NBER Working Paper No. 13303

August 2007

JEL No. C2,I2,L1,O1

\begin{abstract}
This paper examines how schools choose class size and how households sort in response to those choices. Focusing on the highly liberalized Chilean education market, we develop a model in which schools are heterogeneous in an underlying productivity parameter, class size is a component of school quality, households are heterogeneous in income and hence willingness to pay for school quality, and schools are subject to a class-size cap. The model offers an explanation for two distinct empirical patterns observed among private schools that accept government vouchers: (i) There is an inverted-U relationship between class size and household income in equilibrium, which will tend to bias cross-sectional estimates of the effect of class size on student performance. (ii) Some schools at the class size cap adjust prices (or enrollments) to avoid adding another classroom, which produces stacking at enrollments that are multiples of the class size cap. This generates discontinuities in the relationship between enrollment and household characteristics at those points, violating the assumptions underlying regression-discontinuity (RD) research designs. This result suggests that caution is warranted in applying the RD approach in settings in which parents have substantial school choice and schools are free to set prices and influence their enrollments.
\end{abstract}

Miguel Urquiola

Columbia University

SIPA and Economics Department

1022 IAB, MC 3308

420 West 118th Street

New York, NY 10027

and NBER

msu2101@columbia.edu

Eric Verhoogen

Columbia University

SIPA and Economics Department

1022 IAB, MC 3308

420 West 118th Street

New York NY 10027

eric.verhoogen@columbia.edu 


\section{Introduction}

There has been a long and heated debate on whether class-size reductions improve educational performance. Hanushek (1995, 2003) reviews an extensive literature and concludes that class size has no systematic effect on student achievement in either developed or developing countries. Krueger (2003), Kremer (1995) and others have countered that this conclusion is based largely on cross-sectional evidence and subject to multiple potential sources of bias, including the endogenous sorting of students into classes of different sizes, and have called for further analyses using experimental and quasi-experimental designs. In the latter category, an influential approach has been the regression-discontinuity (RD) design of Angrist and Lavy (1999), which exploits the discontinuous relationship between enrollment and class size that results from class-size caps. ${ }^{1}$

Despite a general awareness of the possible endogeneity of class size, relatively little attention has been paid to how schools choose class size or to how households sort in response to those choices. In this paper, we develop a model of class-size choices by heterogeneous schools and of school choices by heterogeneous households, show that two central predictions are borne out in data on Chilean schools, and argue that these findings have important implications for attempts to estimate the effect of class size on student outcomes. Chile's educational market is well-suited to such an investigation in part because private schools account for approximately half of the market, and a majority of them are operated on a for-profit basis. This makes it straightforward to specify schools' objective functions - an otherwise difficult task in many public-sector contexts.

In the model, schools are assumed to be monopolistically competitive, to be heterogeneous in an underlying productivity parameter, and to offer quality-differentiated "products," where class size is a component of school quality. Households are assumed to be heterogeneous in income and hence in willingness to pay for quality. Schools face three constraints, corresponding to real restrictions faced by private schools that accept vouchers in Chile: (1) a class size cap at 45 students; (2) an integer constraint on the number of classrooms; and (3) the restriction that enrollment (a choice variable of schools) cannot exceed demand.

The model delivers two main empirical predictions, both of which find support in the data. First, there is an inverted-U relationship between class size and household income in cross-section.

\footnotetext{
${ }^{1}$ The RD approach has also been used to study the effects of class size by Hoxby (2000) in the U.S., Dobbelsteen, Levin, and Oosterbeek (2002) in Holland, Browning and Heinesen (2003) in Denmark, Asadullah (2005) in Bangladesh, Jakubowski and Sakowski (2005) in Poland, Bressoux, Kramarz, and Prost (2005) and Piketty and Valdenaire (2006) in France, Wössmann (2005) in ten European countries, and Urquiola (2006) in Bolivia.
} 
The model predicts that higher-income households sort into higher-productivity, higher-quality schools, as one might expect. The inverted $U$ arises from the interaction of two effects: higher productivity enables schools to fill up their existing classrooms, and it also leads them to add classrooms and reduce class size to appeal to higher-income households. The former tends to dominate at lower levels of productivity, and the latter at higher levels. The inverted-U relation between class size and income will tend to confound attempts to estimate the effect of class size in cross-sectional regressions.

Second, in the presence of the class-size cap and the integer constraint on the number of classrooms, schools at the cap adjust price (or enrollment) to avoid having to add an additional classroom. This results in stacking at enrollment levels that are multiples of 45 . Because higher-income households sort into higher-productivity schools, the stacking implies discontinuous changes in average family income and hence in other correlates of income, such as mothers' schooling, at these multiples. The resulting discontinuities violate the assumptions underlying the $\mathrm{RD}$ designs that have been used to estimate the effect of class size. Our results thus provide a concrete illustration of how endogenous sorting around discontinuities may invalidate RD designs (Lee, forthcoming; McCrary, forthcoming). We view these results as a cautionary note regarding the application of such designs in contexts where schools are able to set prices and influence their enrollments, and parents have substantial school choice. As we discuss below, we have no reason to believe that this conclusion generalizes to the public-school settings typically studied, in which students are required to attend local schools and in which schools cannot control their enrollments but rather react mechanically to them.

In addition to the papers cited above, this paper is related to a growing body of theoretical and empirical work on sorting in education markets, including Manski (1992), Epple and Romano (1998), Clotfelter (1999), Epple, Figlio, and Romano (2002), Epple and Romano (2002), Nesheim (2002), Caucutt (2002), Nechyba (2003), Bayer, McMillan, and Rueben (2004), Altonji, Huang, and Taber (2005), Urquiola (2005), Epple, Romano, and Sieg (2006), Hsieh and Urquiola (2006), Rothstein (2006), and Ferreyra (2007). Much of this work is focused on the impact of greater school choice either through greater school district availability or through vouchers - on sorting outcomes. The distinctive aspect of this paper is our focus on the role of institutional constraintsthe class-size cap and the integer constraint - in a market that is already largely liberalized.

One caveat is that this paper does not consider the role of peer effects, which play a central role 
in much of the previous theoretical work on sorting in educational markets (Epple and Romano, 1998, 2002; Epple, Figlio, and Romano, 2002). In many of these models, schools are essentially passive "clubs" whose main attribute is the average ability and income of their students. In our model, as in Epple, Romano, and Sieg (2006), schools actively choose the level of educational quality to supply. It is difficult to integrate both the peer-effects and the quality-choice elements in an analytically tractable model. Epple, Romano, and Sieg (2006) maintain both elements, but must rely on numerical methods to compute equilibria. Our approach is to abstract from peer effects in order to arrive at analytical results. In the long run it would clearly be desirable to develop an analytically tractable model that combines both elements.

This paper is also related to work on quality choice by firms (Mussa and Rosen, 1978; Gabszewicz and Thisse, 1979; Shaked and Sutton, 1982; Anderson and de Palma, 2001). The structure of the theoretical model has many elements in common with the framework of Verhoogen (2007), which models quality choice by heterogeneous Mexican firms facing heterogeneous consumers in the domestic and export markets.

Finally, in seeking to understand the mechanisms behind the determination of class size, we view our work as complementary to Lazear (2001), which focuses on how schools allocate students with heterogeneous levels of self-discipline into classes of different sizes. We abstract from sorting within schools and instead focus on sorting between schools with different average class sizes.

The remainder of the paper is organized as follows. Section 2 provides institutional background, and section 3 sets out the model. Section 4 describes the data. Section 5 discusses testable implications and presents the results. Section 6 concludes.

\section{Chile's School System}

There are three main types of schools in Chile:

1. Public or municipal schools are run by roughly 300 municipalities which receive a perstudent "voucher" payment from the central government. These schools cannot turn away students unless oversubscribed, and are limited to a maximum class size of $45 .^{2}$ In most municipalities, they are the suppliers of last resort.

\footnotetext{
${ }^{2}$ In some instances schools are temporarily authorized to have classes of 46 or 47 , but they receive no payments for the students above 45 .
} 
2. Private subsidized or voucher schools are independent, and since 1981 have received exactly the same per student subsidy as municipal schools. ${ }^{3}$ They are also constrained to a maximum class size of 45 , but, unlike public schools, have wide latitude regarding student selection.

3. Private unsubsidized schools are independent, do not accept vouchers and receive no other explicit subsidies, and are not bound by the class-size cap.

Parents can use the per-student voucher in any public or private voucher school that is willing to accept their children. In 2003, private schools (both voucher and unsubsidized) accounted for about 45 percent of all schools, and voucher schools alone accounted for about 36 percent. In urban areas, these shares were 62 and 48 percent, respectively. Private schools can be explicitly for-profit, and using their tax status to classify them, Elacqua (2005) calculates that about 70 percent of them are indeed operated as such. Further, even non-profit schools can legally distribute dividends to principals or board members. A handful of private schools are run by privately or publicly held corporations that control chains of schools, but the modal one is owned and managed by a single principal/entrepreneur.

Public primary schools are not allowed to charge "add on" tuition supplemental to the voucher subsidy. ${ }^{4}$ While initially voucher private schools were subject to the same constraint, this restriction was eased beginning in 1994. At present, they can charge tuition as high as approximately 1.7 times the voucher payment. In practice, this constraint appears not to be important for most voucher schools; in 2006, for instance, fewer than 4 percent of them had per-student revenues within 25 percent of the tuition cap. ${ }^{5}$ The resources these institutions raise through tuition are equal to about 20 percent of their state funding.

Rather than attempt to analyze the entire Chilean educational sector, we narrow our focus in four important ways. First, we restrict attention to primary (K-8) schools because class size, a central variable in our analysis, is more clearly defined at the primary than at the secondary level. Second, we focus on private schools since, as mentioned above, we can plausibly assume that they are profit-maximizing. Third, we focus on urban areas because we want to consider settings where enrollment and class size are determined by schools' and households' choices, and not constrained

\footnotetext{
${ }^{3}$ The payment varies somewhat by location, but within an area voucher and municipal schools receive equal payments. For further details on the creation of the voucher system, see Hsieh and Urquiola (2006).

${ }^{4}$ Public secondary schools can charge add-ons, but in practice very few do.

${ }^{5}$ The administrative data this figure is based on contain information on average revenue and not posted prices. The former can be lower than posted tuition if some students receive discounts.
} 
by the size of the market, as could happen in rural areas. ${ }^{6}$ Fourth, we focus on voucher schools, the private schools subject to the class-size cap, and not on unsubsidized schools. We do so in part because we are primarily interested in how the class-size cap affects sorting outcomes, and in part because the unsubsidized schools serve a very distinct, elite population, ${ }^{7}$ and are governed by considerations that would be difficult to incorporate tractably into our theoretical framework. ${ }^{8}$

A final relevant fact is that as elsewhere, primary schools in Chile are not large; 95 percent of urban ones have fewer than 135 students in the $4^{\text {th }}$ grade. ${ }^{9}$ As Figure 1 illustrates, they run relatively few classes per grade. In 2002, for instance, 53 percent of urban private schools had only one $4^{\text {th }}$ grade class, while 86 and 95 percent had two or fewer or three or fewer, respectively. Public schools run a slightly higher average number of classes, but 91 percent of them still operate three or fewer $4^{\text {th }}$ grades. While in theory schools could combine students from more than one grade into a single classroom, in practice very few do, especially in the urban areas we focus on. In 2002, for instance, 4.3 percent of urban voucher schools reported they combined more than one grade into a class. ${ }^{10}$ These facts motivate the integer constraint in our model.

\section{The Model}

This section develops a model of quality differentiation and sorting in the Chilean school market. We model parents' demand for education in a standard discrete-choice framework with quality differentiation (McFadden, 1974; Anderson, de Palma, and Thisse, 1992). We solve the optimization problem of profit-maximizing voucher schools under realistic constraints. To simplify the model, we take the set of voucher schools as given and abstract from entry decisions. This is a strong assumption, but our view is that including a detailed analysis of entry would add more

\footnotetext{
${ }^{6}$ The qualitative conclusions of our empirical analyses turn out not to be much affected by this restriction.

${ }^{7}$ The summary statistics in Table 1 , discussed in more detail below, indicate that the students attending private unsubsidized schools are from markedly richer households than those in voucher or public schools; for instance, the average household income at the $10^{t h}$ percentile of the income distribution in unsubsidized schools is greater than the average household income at the $90^{t h}$ percentile of the income distribution in voucher schools.

${ }^{8}$ Indeed, in the context of our model, it is a puzzle that many unsubsidized schools refuse to accept vouchers. Essentially all these schools have class sizes below 45, and while we do not have reliable data on their tuition, it appears that many of them also charge average fees well below the maximum allowed for voucher schools. Anecdotally, it appears that an important reason for why these schools do not accept vouchers is that exclusivity is part of their appeal. This appears to be related to peer effects and considerations of social status that are difficult to model tractably.

${ }^{9}$ As discussed below, we focus primarily on $4^{\text {th }}$ grade observations because our testing data are at that grade level. The results for other grades, however, are quite similar.

${ }^{10}$ The administrative data do not allow us to discern how often this happened specifically at the 4th grade level, the one we focus on below. They simply report that the school did this for some combination of grades.
} 
tedious complication than real insight. Under the assumption that each school thinks of itself as small relative to the market as a whole, the extent of entry would not affect the optimizing decisions of particular schools, and our two main implications would continue to hold. It is worth emphasizing that our two main implications do not hold for all possible parameter values in our model. Rather, we show that there exists a set of parameter values for which the implications do hold and in Section 4 we examine whether there is empirical support for them.

\subsection{Demand}

There is a continuum of households of mass $M$, heterogeneous in income. Each is assumed to have one child and to enroll the child in a school. The parameter $\lambda$, discussed in more detail below, indexes schools. Let $x(\lambda), n(\lambda)$ and $p(\lambda)$ represent the enrollment, number of classrooms and tuition of school $\lambda$. We assume that school quality is observed by households and depends on enrollment, the number of classrooms, and $\lambda$ in a manner to be made clear below. Households are assumed to have the following indirect utility function:

$$
U(p(\lambda), q(x(\lambda), n(\lambda), \lambda) ; \theta)=\theta q(x(\lambda), n(\lambda), \lambda)-p(\lambda)+\varepsilon
$$

where $q(x(\lambda), n(\lambda), \lambda)$ is school quality and $\varepsilon$ is a random term capturing the utility of a particular household-school match. This specification follows from a direct utility function in which households have identical utility functions and differ only in income. ${ }^{11}$ The parameter $\theta$ represents households' willingness to pay for quality, and is a monotonically increasing function of household income. We assume that $\theta$ has a distribution $g(\theta)$ with positive support over $(\underline{\theta}, \bar{\theta})$ where $\underline{\theta}, \bar{\theta}>0$; this distribution reflects the underlying distribution of income among households. We assume the random-utility term $\varepsilon$ is i.i.d. across households with a double-exponential distribution with

c.d.f. $F(\varepsilon)=\exp \left[-\exp \left(-\frac{\varepsilon}{\mu}+\chi\right)\right],{ }^{12}$ where $\mu$ is a positive constant that captures the degree of

\footnotetext{
${ }^{11}$ Suppose:

$$
\widetilde{U}(z, q)=u(z)+q+\widetilde{\varepsilon}
$$
}

where $z$ is a non-differentiated numeraire good, $q$ is the quality of education, $\widetilde{\varepsilon}$ is a mean-zero random term, and the sub-utility function $u(\cdot)$ has $u^{\prime}(\cdot)>0$ and $u^{\prime \prime}(\cdot)<0$. If households are on their budget constraint, then indirect utility is:

$$
\widetilde{U}(p, q ; y)=u(y-p)+q+\widetilde{\varepsilon}
$$

Taking a first-order approximation of $u(\cdot)$ around $y$, and setting $\theta \equiv 1 / u^{\prime}(y), U \equiv \frac{\widetilde{U}}{u^{\prime}(y)}-\frac{u(y)}{u^{\prime}(y)}$, and $\varepsilon \equiv \frac{\widetilde{\varepsilon}}{u^{\prime}(y)}$, we have (1). Note that the $\frac{u(y)}{u^{\prime}(y)}$ term is constant across schools and does not affect the household's choice probabilities.

${ }^{12}$ We assume $\chi=0.5772$ (Euler's constant), ensuring that the expectation of $\varepsilon$ is zero. 
differentiation between schools. ${ }^{13}$

A standard derivation yields the probability that a household chooses school $\lambda$, conditional on having willingness to pay for quality $\theta$ and on the qualities and prices of all schools: ${ }^{14}$

$$
s(\lambda \mid \theta, q(\cdot), p(\cdot))=\frac{1}{\Omega(\theta)} \exp \left(\frac{\theta q(x(\lambda), n(\lambda), \lambda)-p(\lambda)}{\mu}\right)
$$

where

$$
\Omega(\theta) \equiv \int_{\underline{\lambda}}^{\bar{\lambda}} \exp \left(\frac{\theta q(x(\tilde{\lambda}), n(\tilde{\lambda}), \tilde{\lambda})-p(\tilde{\lambda})}{\mu}\right) f(\tilde{\lambda}) \mathrm{d} \tilde{\lambda}
$$

We assume that schools cannot discriminate among households, and hence that price and quality are equal for all households in a given school. As is common in monopolistic-competition models, we will treat individual schools as small relative to the market as a whole, and assume that they ignore their effect on the aggregate $\Omega(\theta)$.

The expected market share of school $\lambda$, integrating over all households, is:

$$
s(q(x(\lambda), n(\lambda), \lambda), p(\lambda))=\int_{\underline{\theta}}^{\bar{\theta}} s(\lambda \mid \theta, q(x(\lambda), n(\lambda), \lambda), p(\lambda)) g(\theta) \mathrm{d} \theta
$$

Expected demand for school $\lambda$ is then:

$$
d(q(x(\lambda), n(\lambda), \lambda), p(\lambda))=M s(q(x(\lambda), n(\lambda), \lambda), p(\lambda))
$$

The key implications of this demand specification are that demand for school $\lambda$ is declining in price and increasing in quality, and that higher- $\theta$ households are more sensitive to quality for a given price. Note that the specification combines horizontal differentiation, in the sense that if all schools' tuitions are equal each will face positive demand with positive probability, with vertical differentiation, in the sense that if tuitions are equal, higher-quality schools will face higher demand. Throughout we will assume schools are risk-neutral, and ignore the fact that the expression for $d(\cdot)$ represents an expectation.

It will be convenient to define the expected willingness to pay of households that send their

\footnotetext{
${ }^{13}$ As $\mu \rightarrow 0$, the distribution of household-school-specific utility terms collapses to a point, and the model approaches perfect competition.

${ }^{14}$ See for example Anderson, de Palma, and Thisse (1992, theorem 2.2, p. 39).
} 
children to school $\lambda$ :

$$
\begin{aligned}
\Theta(q(x(\lambda), n(\lambda) ; \lambda), p(\lambda)) & \equiv E(\theta \mid q(x(\lambda), n(\lambda) ; \lambda), p(\lambda)) \\
& =\int_{\underline{\theta}}^{\bar{\theta}} \theta\left[\frac{s(\lambda \mid \theta, q(x(\lambda), n(\lambda), \lambda), p(\lambda)) g(\theta)}{s(q(x(\lambda), n(\lambda), \lambda), p(\lambda))}\right] \mathrm{d} \theta
\end{aligned}
$$

where by Bayes' rule the term in brackets represents the probability density of $\theta$ conditional on households sending their children to school $\lambda$.

\subsection{Production}

We now think of $\lambda$ as an exogenously fixed productivity parameter in which schools are heterogeneous. It can be interpreted as the ability of the school principal/entrepreneur. ${ }^{15}$ We assume that there is a continuum of schools with continuous density $f(\lambda)$ over the interval $[\underline{\lambda}, \bar{\lambda})$. Each school is uniquely identified by its value of $\lambda$, which justifies our use of $\lambda$ as an index above.

Each school is constrained to offer just one "product," and is assumed to produce quality with a technology:

$$
q(x, n ; \lambda)=\lambda \ln \left(\frac{T}{x / n}\right)
$$

where $x$ is enrollment, $n$ is the number of classrooms, the denominator is class size, and $T$ is a constant that represents the technological maximum of class size. The term in parentheses is by assumption always greater than or equal to one. This specification captures the idea that the larger is class size the less teacher attention is available for each individual student. ${ }^{16}$ Note that a given reduction in class size raises quality more at higher- $\lambda$ schools. This complementarity will be crucial in what follows.

In order to guarantee an interior solution for the school's optimization problem we must impose a lower bound on the degree of differentiation between schools. The condition:

$$
\mu>\bar{\lambda} \bar{\theta}
$$

\footnotetext{
${ }^{15}$ In a more complex, dynamic model, one might think of $\lambda$ as reputation. The important point is that it affects households' perceptions of quality and is unaffected by schools' decisions in the short run.

${ }^{16}$ An interesting extension might be to include an endogenous term in the numerator representing teacher quality, an additional choice variable for schools. We leave this task for future work, in part because we do not have data on teacher salaries or other teacher characteristics.
} 
will be sufficient. Intuitively, this limits the extent to which demand for a school increases with a given class-size reduction.

We suppose that there is a fixed cost $F_{s}$ of running a school, a fixed cost $F_{c}$ of operating a classroom, and a constant variable cost $c$ for each student. Recall that $p$ is tuition, and let $\tau$ be the per-student subsidy that schools receive from the government. Profit is then:

$$
\pi(p, n, x ; \lambda)=(p+\tau-c) x-n F_{c}-F_{s}
$$

There is assumed to be no cost of differentiation; hence every school differentiates its "product" and has a monopoly over the product it offers.

\subsection{Schools' Optimization Problem}

The problem facing schools is to maximize profit over the choice of tuition, enrollment, and the number of classrooms:

$$
\max _{p, x, n} \pi(p, x, n ; \lambda)
$$

This optimization is subject to three constraints:

1. The number of classrooms must be a positive integer

$$
n \in \mathbb{N}
$$

where $\mathbb{N}$ is the set of natural numbers $\{1,2,3, \ldots\}$.

2. Class size cannot exceed the class-size cap:

$$
\frac{x}{n} \leq 45
$$

3. Enrollment cannot exceed demand:

$$
x \leq d(q(x, n ; \lambda), p)
$$

where $q(\cdot)$ is given by $(6)$ and $d(\cdot)$ by $(4)$. 
Although the first two constraints are designed to mimic the institutional environment in Chile, they are likely to apply more generally. It is common in many countries for primary schools to have a relatively small number of classrooms per grade and to be subject to class-size caps. The third constraint clearly applies to all schools. ${ }^{17}$

\subsection{Characterization of Equilibrium}

The integer restriction complicates the solution of schools' optimization problems, since we cannot simply solve a set of first-order conditions. A common approach to such problems is to first relax this constraint, then compare solutions with and without the relaxation. This is how we proceed below. In the main text, we report key results; derivations of those results appear in Appendix A, with section numbers corresponding to the cases.

\section{Case 1: Divisible Classrooms}

If the integer constraint (10) is relaxed, it turns out that in equilibrium there is a critical value of the entrepreneurial-ability parameter, call it $\alpha$, to the right of which the class-size cap does not bind and to the left of which it does bind. Consider each of these sub-cases in turn.

\section{Sub-Case 1.1: Class-Size Cap Non-Binding}

If $\lambda>\alpha$ and the cap does not bind, then in equilibrium schools' optimal choices are defined implicitly by the following:

$$
\begin{aligned}
p^{*}(\lambda) & =\mu+c-\tau+\lambda \Theta\left(q\left(x^{*}(\lambda), n^{*}(\lambda) ; \lambda\right), p^{*}(\lambda)\right) \\
x^{*}(\lambda) & =d\left(q\left(x^{*}(\lambda), n^{*}(\lambda) ; \lambda\right), p^{*}(\lambda)\right) \\
n^{*}(\lambda) & =\frac{1}{F_{c}} \lambda x^{*}(\lambda) \Theta\left(q\left(x^{*}(\lambda), n^{*}(\lambda) ; \lambda\right), p^{*}(\lambda)\right)
\end{aligned}
$$

where $\Theta(\cdot)$ is given by $(5), d(\cdot)$ is given by $(4)$, and the asterisks indicate equilibrium values. In order for the second-order conditions for a maximum to be satisfied, it must be the case that:

$$
\Psi \equiv \Theta\left(q\left(x^{*}(\lambda), n^{*}(\lambda) ; \lambda\right), p^{*}(\lambda)\right)-\frac{\lambda \sigma_{\theta \mid \lambda}^{2}}{\mu}>0
$$

\footnotetext{
${ }^{17}$ The third constraint ends up binding in every case we present here, and we could treat it as an equality constraint or substitute $d(\cdot)$ for $x$ in (8) and (9). But there exist realistic cases in which it would not bind-i.e. if there were a tuition constraint. For conceptual clarity, we leave the constraint as an inequality.
} 
where $\sigma_{\theta \mid \lambda}^{2}$ is the variance of $\theta$ among households with children attending school $\lambda$ in equilibrium. ${ }^{18}$ Assumption (7) guarantees that this condition holds. (See Appendix A.1.1.) Unfortunately, there is no explicit analytical solution to (13a)-(13c). Nonetheless, using the implicit function theorem, we can sign the relationship between the various endogenous variables and the underlying productivity parameter, $\lambda$. In particular:

$$
\begin{aligned}
& \frac{\partial p^{*}}{\partial \lambda}>0 \\
& \frac{\partial x^{*}}{\partial \lambda}>0 \\
& \frac{\partial n^{*}}{\partial \lambda}>0 \\
& \frac{\partial \Theta^{*}}{\partial \lambda}>0 \\
& \frac{\partial}{\partial \lambda}\left(\frac{x^{*}}{n^{*}}\right)<0
\end{aligned}
$$

where $\Theta^{*}$ is shorthand for the equilibrium value of $\Theta(\cdot)$ for a given $\lambda$. In equilibrium, higher- $\lambda$ schools charge higher tuition, have larger enrollments, operate more classrooms, have smaller class sizes, and attract students whose families are on average wealthier and have higher willingness to pay for quality. All of these relationships are monotonic in $\lambda$.

In Figure 2, which plots class size vs. $\lambda$ in the divisible-classrooms case, this sub-case corresponds to the declining portion of the curve, to the right of the critical value $\alpha$. Intuitively, the fact that class size is declining in $\lambda$ is a consequence of the fact that $\lambda$ and class-size reductions are complementary in the quality production function (6).

\section{Sub-Case 1.2: Class-Size Cap Binding}

If $\lambda \leq \alpha$ and the class-size cap binds, then in equilibrium schools' optimal choices are defined

${ }^{18}$ That is, define:

$$
\sigma_{\theta \mid \lambda}^{2} \equiv \int_{\underline{\theta}}^{\bar{\theta}}\left(\theta-\Theta\left(q\left(x^{*}(\lambda), n^{*}(\lambda) ; \lambda\right), p^{*}(\lambda)\right)\right)^{2}\left[\frac{s\left(\lambda \mid \theta, q\left(x^{*}(\lambda), n^{*}(\lambda), \lambda\right), p^{*}(\lambda)\right) g(\theta)}{s\left(q\left(x^{*}(\lambda), n^{*}(\lambda), \lambda\right), p^{*}(\lambda)\right)}\right] \mathrm{d} \theta
$$


implicitly by:

$$
\begin{aligned}
p^{*}(\lambda) & =c-\tau+\mu+\frac{F_{c}}{45} \\
x^{*}(\lambda) & =d\left(q\left(x^{*}(\lambda), n^{*}(\lambda) ; \lambda\right), p^{*}(\lambda)\right) \\
n^{*}(\lambda) & =\frac{x^{*}(\lambda)}{45}
\end{aligned}
$$

The slopes with respect to $\lambda$ in this sub-case are:

$$
\begin{aligned}
& \frac{\partial p^{*}}{\partial \lambda}=0 \\
& \frac{\partial x^{*}}{\partial \lambda}>0 \\
& \frac{\partial n^{*}}{\partial \lambda}>0 \\
& \frac{\partial \Theta^{*}}{\partial \lambda}>0 \\
& \frac{\partial}{\partial \lambda}\left(\frac{x^{*}}{n^{*}}\right)=0
\end{aligned}
$$

Although class size and price are constant, enrollment, the number of classrooms, and average household income are increasing in the productivity parameter. Average household income is increasing in $\lambda$ because $\lambda$ raises quality conditional on class size. It is notable that profits are also increasing in $\lambda$, even though price is constant, because enrollment is increasing in $\lambda$ and schools charge a mark-up over costs. In Figure 2, this sub-case corresponds to the portion of the curve to the left of $\alpha$ where class size is flat at 45 .

The critical value $\alpha$ is defined implicitly by the equation

$$
\alpha \Theta\left(q\left(x^{*}(\alpha), n^{*}(\alpha) ; \alpha\right), p^{*}(\alpha)\right)=\frac{F_{c}}{45}
$$

This is the value of $\lambda$ at which $\frac{x}{n}=45$ in the first sub-case above. Note that there is no guarantee that $\alpha \in(\underline{\lambda}, \bar{\lambda})$, i.e. that the class-size cap will be binding on any schools in the market. At the critical value, the optimal choices $p^{*}, x^{*}$, and $n^{*}$ are equal in the two sub-cases (cap binding, cap non binding). Hence over the entire range of $\lambda$ we have that $p^{*}, x^{*}, n^{*}$ and $\Theta^{*}$ are continuous; $p^{*}$ is weakly monotonically increasing; $x^{*}, n^{*}$ and $\Theta^{*}$ are strictly monotonically increasing; and $\frac{x^{*}}{n^{*}}$ is weakly monotonically decreasing. 


\section{Case 2: Indivisible Classrooms}

Now add the restriction that the number of classrooms must be an integer (10). Our strategy for dealing with the integer constraint is first to characterize the optimal choices of schools for a given number of classrooms, and then to characterize the sets of schools that choose each integer number of classrooms.

\section{Fixed Number of Classrooms}

To begin, suppose that $n$ is fixed and think of it as a parameter. It will turn out that for a given $n$ there is a single critical value of $\lambda$, call it $\beta(n)$, below which the class-size cap does not bind and above which it binds. Again consider the two sub-cases in turn.

\section{Sub-Case 2.1: Class-Size Cap Non-Binding}

If $\lambda \leq \beta(n)$ and the class-size cap does not bind, then schools' optimal choices are implicitly defined by:

$$
\begin{aligned}
& p^{*}(n, \lambda)=\mu+c-\tau+\lambda \Theta\left(q\left(x^{*}(n, \lambda) ; n, \lambda\right), p^{*}(n, \lambda)\right) \\
& x^{*}(n, \lambda)=d\left(q\left(x^{*}(n, \lambda) ; n, \lambda\right), p^{*}(n, \lambda)\right)
\end{aligned}
$$

Price and average willingness to pay (i.e. average household income) are unambiguously increasing in $\lambda$ :

$$
\begin{aligned}
& \frac{\partial p^{*}}{\partial \lambda}>0 \\
& \frac{\partial \Theta^{*}}{\partial \lambda}>0
\end{aligned}
$$

There is a subtlety in the relationship between enrollment and $\lambda$. On one hand, there is a direct effect of a higher $\lambda$ on demand: for a given class size, households prefer higher- $\lambda$ schools. On the other hand, there is an indirect effect: from (6), at higher values of $\lambda$ a given increase in enrollment has a larger negative effect on quality and hence on demand. It is theoretically possible in this case that the latter effect dominates, making it optimal for higher- $\lambda$ schools to raise prices such that enrollment, conditional on a given number of classrooms, is decreasing in $\lambda$. In that case, our testable implications (discussed in the introduction and in more detail below) 
do not hold. We focus instead on the case where enrollment is increasing in $\lambda$. A necessary and sufficient condition for this, which we assume hereafter, is: ${ }^{19}$

$$
\ln \left(\frac{n T}{x^{*}(n, \lambda)}\right)>\frac{\Theta\left(q\left(x^{*}(n, \lambda) ; n, \lambda\right), p^{*}(n, \lambda)\right)}{\Psi}
$$

where $\Psi$ is defined as in (14). Under this assumption, we have

$$
\frac{\partial x^{*}}{\partial \lambda}>0
$$

Since $n$ is fixed, (23) implies that $\frac{\partial}{\partial \lambda}\left(\frac{x^{*}}{n}\right)>0$; for a given number of classrooms, class size is increasing in $\lambda$. That is, conditional on $n$, higher- $\lambda$ schools are better able to fill their classrooms.

\section{Sub-Case 2.2: Class-Size Cap Binding}

If $\lambda>\beta(n)$ and the class-size cap binds, then we have two endogenous variables and two binding constraints. The constraints pin down the values of $p$ and $x$ :

$$
\begin{aligned}
& p^{*}(n, \lambda)=\mu \ln \Sigma-\mu \ln (45 n) \\
& x^{*}(n, \lambda)=45 n
\end{aligned}
$$

where

$$
\Sigma \equiv \int_{\underline{\theta}}^{\bar{\theta}} \frac{1}{\Omega(\theta)}\left(\frac{T}{45}\right)^{\frac{\theta \lambda}{\mu}} g(\theta) \mathrm{d} \theta
$$

The slopes with respect to $\lambda$ are:

$$
\begin{aligned}
\frac{\partial p^{*}}{\partial \lambda} & >0 \\
\frac{\partial x^{*}}{\partial \lambda} & =\frac{\partial}{\partial \lambda}\left(\frac{x^{*}}{n}\right)=0 \\
\frac{\partial \Theta^{*}}{\partial \lambda} & >0
\end{aligned}
$$

\footnotetext{
${ }^{19}$ If we replace the production function for quality (6) by a general function $q(x, n ; \lambda)$, then the condition is:

$$
-\frac{\partial^{2} q}{\partial x \partial \lambda}<\left(\frac{\sigma_{\theta \mid \lambda}^{2}}{\mu \Theta^{*}} \frac{\partial q}{\partial x}+\frac{1}{x}\right) \frac{\partial q}{\partial \lambda}
$$

which makes it clear that the indirect effect of higher $\lambda$ described above (represented by $\frac{\partial^{2} q}{\partial x \partial \lambda}$ ) must be small in magnitude relative to the direct effect (represented by $\frac{\partial q}{\partial \lambda}$ ).
} 
The critical value $\beta(n)$ for a given $n$ is defined implicitly by the equation:

$$
\beta(n) \Theta\left(q\left(x^{*}(\beta(n)) ; n, \beta(n)\right), p^{*}(\beta(n))\right)=\mu \ln \Sigma-\mu \ln (45 n)-c+\tau-\mu
$$

The critical value of $\lambda$ is the point at which class size reaches 45 in sub-case 2.1. At this value, the optimal choices $p^{*}$ and $x^{*}$ are the same in the two sub-cases. Hence for a given $n, p^{*}, x^{*}$, and $\Theta^{*}$ are continuous at $\beta(n), p^{*}$ and $\Theta^{*}$ are strictly monotonically increasing in $\lambda$, and $x^{*}$ and $\frac{x^{*}}{n}$ are weakly monotonically increasing in $\lambda$.

\section{Optimal Choice of Number of Classrooms}

Now consider the issue of which integer number of classrooms schools choose. Let

$$
\tilde{\pi}(n, \lambda) \equiv \pi\left(p^{*}(n, \lambda), x^{*}(n, \lambda) ; n, \lambda\right)
$$

be school $\lambda$ 's optimal profit when the number of classrooms is fixed at $n$, where $p^{*}(n, \lambda)$ and $x^{*}(n, \lambda)$ are given by (20a)-(20b) for $\lambda \leq \beta(n)$ and (24a)-(24b) for $\lambda>\beta(n)$. Define $\Lambda_{k}$ to be the set of all schools for which a given integer $k$ is the optimal number of classrooms:

$$
\Lambda_{k}=\{\lambda: \tilde{\pi}(k, \lambda) \geq \tilde{\pi}(j, \lambda) \forall j \neq k, j \in \mathbb{N}\}
$$

The following lemma characterizes the sets $\Lambda_{k}$ :

Lemma 1. There exist unique positive integers $\underline{k}$ and $\bar{k}$ and a unique set of critical values $\nu_{\underline{k}}, \nu_{\underline{k}+1}, \ldots \nu_{\bar{k}-1}, \nu_{\bar{k}}$ such that:

$$
\Lambda_{k}=\left\{\lambda: \nu_{k-1} \leq \lambda<\nu_{k}\right\} \text { for } k=\underline{k}, \underline{k}+1, \ldots, \bar{k}
$$

where $\underline{\lambda}=\nu_{\underline{k}-1}<\nu_{\underline{k}}<\ldots<\nu_{\bar{k}-1}<\nu_{\bar{k}}=\bar{\lambda}$.

The proof is in Appendix A.2.3. The lemma indicates that the set of schools can be partitioned into a set of intervals, $\left[\nu_{\underline{k}-1}, \nu_{\underline{k}}\right),\left[\nu_{\underline{k}}, \nu_{\underline{k}+1}\right),\left[\nu_{\underline{k}+1}, \nu_{\underline{k}+2}\right)$ etc., where the optimal integer number of classrooms is $\underline{k}$ in the first interval, $\underline{k}+1$ in the next, $\underline{k}+2$ in the next, and so on. Within each of the subsets $\Lambda_{k}$ the above results for fixed $n$ hold. 
Appendix A.2.4 shows that at the critical values $\nu_{\underline{k}}, \nu_{\underline{k}+1}, \ldots, \nu_{\bar{k}-1}$, enrollment is strictly increasing, class size is weakly decreasing, and average willingness to pay is strictly increasing in $\lambda .^{20}$ The fact that average willingness to pay is strictly increasing at the critical values, and that it is strictly increasing between the critical values (refer to (21b) and (26c)), means that in equilibrium average willingness to pay $\Theta^{*}$ is monotonically increasing in $\lambda$ for all $\lambda$.

Note that there is no guarantee that the value of $\lambda$ at which the class-size cap starts to bind for a given integer $k, \beta(k)$, is to the left of the value of $\lambda$ at which it becomes optimal to add an additional classroom, $\nu_{k}$. In the empirical part of the paper, we present evidence consistent with the hypothesis that $\beta(k)<\nu_{k}$ for low values of $k$.

Figure 3 plots class size against $\lambda$ for the case where $\beta(k)<\nu_{k}$ for $k=1$ and $k=2$ but not thereafter. The curve roughly resembles the curve for the divisible-classrooms case (Figure 2), but with an overlaid saw-tooth pattern generated by the integer constraint. The figure exhibits an approximately inverted-U relationship between class size and $\lambda$. It results from the interaction of two effects: (1) conditional on a value of $n$, class size is increasing in $\lambda$, since greater values of $\lambda$ make schools better able to fill their classrooms; and (2) across values of $n$, class size is declining in $\lambda$, since greater $\lambda$ leads schools to increase the number of classrooms, reducing class size.

The inverted- $U$ relationship between class size and $\lambda$ is not itself testable, because $\lambda$ is unobserved. But since $\Theta^{*}$ is strictly increasing in $\lambda$ for all $\lambda$, we would also expect an inverted-U relationship in equilibrium between class size and $\Theta^{*}$. This gives us our first testable implication:

Testable Implication 1 In equilibrium, there is an approximately inverted-U relationship between class size and average household income.

Figure 3 also illustrates that schools between $\beta(1)$ and $\nu_{1}$ have enrollment 45 and schools between $\beta(2)$ and $\nu_{2}$ have enrollment 90. Intuitively, in these regions schools raise tuition rather than incur the fixed cost of starting a new classroom. ${ }^{21}$ Although we do not model the possibility explicitly, one can easily imagine that in the presence of stochasticity in demand and menu costs of changing tuition, schools might turn away potential students for the same reason. ${ }^{22}$ Since average

\footnotetext{
${ }^{20}$ The direction of the change in price at each critical value is ambiguous in this case. The slope $\frac{\partial p}{\partial \lambda}$ is greater when the class-size cap binds than when it does not bind, since higher $\lambda$ leads schools to raise prices to keep class-size pegged at 45. Consequently, price may be greater to the left of $\nu_{k}$ than to the right.

${ }^{21}$ Appendix A.2.2 shows that for a given number of classrooms, tuition $(p)$ is more steeply sloped in $\lambda$ in the region where the class-size cap binds than in the region where the cap does not bind.

${ }^{22}$ In Chile, private schools have wide latitude regarding student selection, and can turn away students for reasons ranging from the desire to maintain a given class size, to the desire to maintain religious uniformity.
} 
household income is monotonically increasing in $\lambda$, the stacking implies discontinuous changes in average household income with respect to enrollment at enrollments of 45, 90, and so on. ${ }^{23}$ More generally, we have our second testable implication:

Testable Implication 2 In equilibrium, schools may stack at enrollments that are multiples of 45, implying discontinuous changes in average household income with respect to enrollment at those points.

It is worth considering briefly what our model predicts for private unsubsidized schools, the elite private schools that do not accept vouchers and are not subject to the class-size cap. In the context of the model, the results for unsubsidized schools would be similar to those for voucher schools in the sub-cases where the class-size cap is not binding. That is, if we were to set the value of the voucher to zero and suppose that $\beta(k)>\nu_{k}$ for all $k$, then the results in sub-cases 1.1 and 2.1 would carry over to unsubsidized schools. In this case, the figure analogous to Figure 3 would not have the flat regions between $\beta(1)$ and $\nu_{1}$ and between $\beta(2)$ and $\nu_{2}$.

\section{Data}

To examine our model's implications, we draw on two sources of information. The first is schoollevel administrative information on grade-specific enrollments and the number of classrooms from the Chilean Ministry of Education; we use these data to calculate average class sizes in each grade. The second source of information is the SIMCE testing system, ${ }^{24}$ which tracks schools' math and language performance. SIMCE data are available at the school level since 1988. Since 1997, they also exist at the individual level and include information on students' household income, parental schooling, and other characteristics from a parental questionnaire sent home with students.

Depending on the year, the SIMCE tests $4^{t h}, 8^{\text {th }}$, or $10^{\text {th }}$ graders. We focus on the $4^{\text {th }}$ grade because as indicated above, class size is best-defined in early primary grades. We focus on the 2002 cross section because it is the most recent $4^{\text {th }}$ grade testing round for which we have data.

\footnotetext{
${ }^{23}$ Technically speaking, as long as the class-size cap is not binding to the right of the critical value, $\nu_{k}$, the model predicts a discontinuity in $\Theta^{*}$ even in the absence of stacking. Average willingness to pay in equilibrium is a smooth, monotonically increasing function of class size. (See the discussions leading up to (58c) and (63) in Appendix A.2.4.) Class size jumps discontinuously at the critical values $\nu_{k}$. Hence $\Theta^{*}$ must also jump at $\nu_{k}$. Our view, however, is that the discontinuity due to stacking is the more empirically important one.

${ }^{24}$ SIMCE, which stands for Sistema de Medición de la Calidad de la Educación (Educational Quality Measurement System), is Chile's standardized testing program.
} 
We note, however, that the general conclusions we obtain emerge in other cross-sections we have analyzed (for instance, the $19994^{\text {th }}$ grade and the $20048^{\text {th }}$ grade waves).

Table 1 presents descriptive statistics for public schools, private voucher schools and public unsubsidized schools. As noted in Section 2, the table indicates that private unsubsidized schools serve a very different demographic group than either the voucher or the public schools. Household income and parents' schooling are markedly higher in the unsubsidized schools. Students' test scores, unsurprisingly, are highly correlated with these measures of socioeconomic status.

\section{$5 \quad$ Results}

We now take our two testable implications to the data. We review each implication, discuss how it relates to the existing literature, and present the empirical results.

\subsection{Class Size and Income in Cross-Section: The Inverted U}

The first testable prediction is an inverted-U relationship between class size and average household income. The upward-sloping portion reflects the fact that low- $\lambda$ schools may have trouble filling their existing classrooms to achieve the desired class size. The downward-sloping portion reflects the fact that higher- $\lambda$ schools find it profitable to restrict class size to appeal to richer households. These mechanisms are consistent with anecdotal evidence from Chile, where there is a widespread perception that many lower-quality voucher schools are small "mom and pop" operations that struggle to fill their classrooms. In contrast, voucher schools run by larger firms have sufficient demand to operate multiple classrooms, and are generally perceived to be of higher quality.

Panel A in Figure 4 plots class size against log average household income among urban voucher schools. The central line plots fitted values of a locally weighted regression of class size on $\log$ income, and the outer lines plot point-wise confidence intervals generated by a bootstrap procedure. ${ }^{25}$ A clear inverted-U pattern is evident. Panel B produces a similar conclusion, using mothers' schooling rather than income on the x-axis. Average class size rises with mothers' schooling up to about the point where the average mother is a high school graduate, and declines thereafter.

\footnotetext{
${ }^{25}$ Using a parametric regression with a fifth-order polynomial produces very similar results, both for the conditional mean and the confidence intervals.
} 
A possible concern with these figures is that the inverted- $U$ pattern may reflect the aggregation of schools across regions, rather than cross-sectional patterns within markets. To examine this possibility, Table 2 reports simple regressions of class size on polynomials in log income (Panel A) and mother's schooling (Panel B) among urban voucher schools. To facilitate interpretation, we use second-order polynomials. Column 1 reports results without region dummies, and Columns 2 and 3 include dummies for 13 regions and 318 municipalities, respectively. The quadratic term is uniformly negative and significant, and not much affected by the regional controls. That is, the inverted-U pattern holds even within narrowly defined urban markets.

The inverted- $U$ finding is relevant to the literature on the effect of class size on student achievement. In this literature, it is common to see cross-sectional estimates that are of the "wrong" sign or essentially equal to zero. Since achievement tends to be strongly correlated with household income and since income is often unobserved (or is observed with error), the invertedU pattern suggests that cross-sectional regressions are likely to understate the effect of class size reductions among lower-income voucher schools and to overstate it among higher-income ones. ${ }^{26}$

Previous work has revealed positive correlations between class size and enrollment and between enrollment and household socioeconomic status among public schools in Israel (Angrist and Lavy, 1999) and Bolivia (Urquiola, 2006), ${ }^{27}$ but to our knowledge our paper is the first to provide either a theoretical rationale or empirical evidence for a non-linear relationship between class size and household income. We conjecture that the inverted-U pattern is likely to arise among private primary schools in other countries.

\subsection{Stacking at Multiples of Class-Size Cap}

Our second testable implication is related to regression discontinuity (RD) designs that exploit the discontinuous relationship between enrollment and class size induced by class-size caps. ${ }^{28}$ Figure 5 shows that the Chilean setting appears to be a promising one for an RD-based evaluation of the effect of class size. The solid line plots the relation between class size and enrollment that

\footnotetext{
${ }^{26}$ Consistent with Figure 4, for instance, we find that a cross-sectional bi-variate regression of test scores on class size among all urban voucher schools results in an insignificant point estimate. If the sample is restricted to schools with mean mothers' schooling below 12 years of age, however, the coefficient is positive and significant. If it is restricted to schools with a mean above 12, it is negative and significant at the 10 percent level.

${ }^{27}$ Mizala and Romaguera (2002) present evidence of a positive correlation between enrollment and household socioeconomic status in Chile.

${ }^{28}$ For overviews and history of the RD design, see Angrist and Krueger (1999), van der Klaauw (2002), and Shadish, Cook, and Campbell (2002).
} 
would be observed if schools mechanically expanded class size with enrollment until reaching the class-size cap, i.e. if class size were determined by:

$$
\left(\frac{x}{n}\right)^{p}=\frac{x}{\operatorname{int}\left(\frac{x-1}{45}\right)+1}
$$

where the superscript $p$ indicates this is the predicted level. This results in a "saw-tooth" pattern in which class size increases one for one with enrollment until, at 46, a new class is added and average class size falls to 23 , with other discontinuities observed at 90, 135, etc. Using data for urban voucher schools for 2002, the circles plot enrollment-cell means of class size. Aggregated to the enrollment-cell level as in this figure, a regression of actual on predicted class size produces an $R^{2}$ greater than 0.9 - a clear "first stage". ${ }^{29}$

The idea behind RD designs, originally proposed by Thistlewaite and Campbell (1960), is that discontinuities like those in Figure 5 can be used to identify the causal effect of class size even if enrollment is systematically related to factors that affect students' outcomes. Intuitively, if enrollment is smoothly related to student characteristics and other factors that affect achievement at multiples of the class-size cap, then for example students in schools with enrollments of 45 provide an adequate control group for those in schools with enrollments of 46 . In such a case, differences in students' performance can be attributed to the very different class sizes they experience.

More formally, consider a standard RD model, assuming one class-size cut-off and a homogeneous effect of class size on test scores (van der Klaauw, 2002):

$$
\begin{aligned}
T S_{i} & =\gamma E\left(C S_{i} \mid X_{i}\right)+f\left(X_{i}\right)+u_{i} \\
E\left(C S_{i} \mid X_{i}\right) & =\eta 1\left(X_{i} \geq \widetilde{X}_{0}\right)+k\left(X_{i}\right)
\end{aligned}
$$

where $i$ indexes schools, $T S_{i}$ is the average $4^{t h}$-grade test score in school $i, C S_{i}$ is average $4^{t h}$ grade class size, $X_{i}$ is $4^{t h}$-grade enrollment, $\widetilde{X}_{0}$ is the value of the class-size cut-off (i.e. 45$), f(\cdot)$ and $k(\cdot)$ are flexible functions of enrollment, and $E\left(\varepsilon_{i} \mid X_{i}\right)=0$. In the present setting this model corresponds to a "fuzzy" (as opposed to "sharp") regression discontinuity design, since, as Figure 5 indicates, enrollment affects but does not perfectly explain class size.

In the context of this model, if $f(\cdot)$ and $k(\cdot)$ are continuous at $\widetilde{X}_{0}$ and the mean of class size

\footnotetext{
${ }^{29}$ For visual clarity, Figure 5 excludes schools that declare $4^{\text {th }}$ grade enrollments above 180 students (less than two percent of all schools), thus focusing on only the first three discontinuities in the enrollment/class size relation.
} 
conditional on enrollment, $E\left(C S_{i} \mid X_{i}\right)$ is discontinuous at $\widetilde{X}_{0}$, then the class-size effect, $\gamma$, is nonparametrically identified at the cut-off (Hahn, Todd, and van der Klaauw, 2001). Intuitively, in a small enough neighborhood around the cut-off, $f(\cdot)$ and $k(\cdot)$ are constant and any discontinuity in test scores can be attributed to the discontinuity in the conditional mean of class size. In practice, one rarely has enough data in neighborhoods around the cut-off to estimate $\gamma$ precisely. As Lee and Card (forthcoming) point out, if $X_{i}$ is discrete, as in our case, one cannot estimate the classsize effect non-parametrically even with an infinite amount of data, and one must therefore choose parametric specifications for $f(\cdot)$ and $k(\cdot)$. If these are specified correctly then they capture all dependence of class size and test scores on enrollment away from the cut-off and the instrumentalvariable (IV) procedure corresponding to (31a)-(31b) will consistently estimate $\gamma$, effectively using only the discontinuity in $E\left(C S_{i} \mid X_{i}\right)$. In our baseline specifications, we use four class-size cut-offs, rather than just one as in (31b), and piecewise linear splines (with "kinks" at the values of the cut-offs) for $f(\cdot)$ and $k(\cdot) \cdot{ }^{30}$

Table 3 reports the results of a standard RD analysis using school-level data from 2002. Column (1) presents the first-stage regression of class size on indicators for whether enrollment is above the first four cut-offs, along with the piecewise linear spline for enrollment. The coefficients on the cut-off indicators are estimates of the average decline in class size at those breaks. ${ }^{31}$ Consistent with the visual evidence in Figure 5, the first one suggests that class size drops by about 17 students at the first threshold. The declines at the first three of the four cut-offs are statistically significant, but become progressively smaller. ${ }^{32}$ In this specification, all standard errors are clustered by enrollment levels, as Lee and Card (forthcoming) suggest is appropriate when the assignment variable (here enrollment) is discrete.

There is prima-facie evidence that the standard RD strategy would generate significant results. Figure 6 presents "raw" enrollment-cell means of math and language test scores, along with the fitted values of a locally weighted regression calculated within each enrollment segment. Particularly around the first cut-off, which accounts for the greatest density of schools, the discrete

\footnotetext{
${ }^{30}$ We return to the possibility of using higher order polynomials below. We note that the piecewise splines are appropriate to the extent that equation (30) suggests that if the class size rule were strictly applied, the slope of the relationship between class size and enrollment would be different in each segment.

${ }^{31}$ For the sake of space, Table 3 and all subsequent ones exclude the small number of schools that declare $4^{t h}$ grade enrollments above 225 (less than one percent of all schools), thus focusing on only the first four discontinuities in the enrollment/class size relation.

${ }^{32}$ Although we omit the results, adding controls for individuals' characteristics has essentially no effect on the key coefficients.
} 
reduction in class size is accompanied by an increase in average test scores. This observation is also borne out by the regression results. Columns 2-3 of Table 3 present reduced-form regressions of average math and language scores, showing positive and significant increases in scores at the first cut-off, and positive (although not significant) increases at subsequent ones. Columns 4-5 report IV specifications, where dummy variables for the first four cut-offs are used as instruments for class size. In both columns, class size appears to have a negative and significant effect on test scores.

Focusing more narrowly around the discontinuities as in van der Klaauw (2002), Columns 1-3 of Table 4 present IV results for bands of 5 students (panels A and C for math and language, respectively) and 3 students (panels B and D) around the first three breaks, omitting the piecewise spline in enrollment. ${ }^{33}$ These are equivalent to simple Wald estimates of the effect of class size within the bands around each cut-off. ${ }^{34}$ Column 4 produces similar estimates pooling all three local samples. ${ }^{35}$ In these pooled samples, the point estimates of the effect of class size on test scores are uniformly negative, although not statistically significant. ${ }^{36}$

One might be tempted to interpret Tables 3 and 4 as producing consistent estimates of the causal effect of class size on achievement. If the second testable implication of our model is correct, however, then the smoothness conditions required for valid RD-based inference are likely to be violated. Recall that the theoretical model predicts a non-negligible mass of schools stacking at enrollments of 45; in Figure 3, for instance, all schools with productivity parameters between $\beta(1)$ and $\nu_{1}$ have enrollment 45, and all those between $\beta(2)$ and $\nu_{2}$ have enrollment 90. Panel A of Figure 7 presents a histogram of $4^{\text {th }}$ grade enrollments among urban voucher schools, and the evidence of such stacking is clear: more than 5 times as many schools report enrollments of 45 as report enrollments of 46 . The same happens at higher cut-offs as well: more than 7 times as many schools have $904^{\text {th }}$ graders as have 91 , for instance. ${ }^{37}$ Panel B shows that there is no evidence of stacking among private unsubsidized schools, which are not subject to the class-size cap. It appears that the stacking among voucher schools is not due to technological factors unrelated to

\footnotetext{
${ }^{33}$ The somewhat erratic results in Column 2 are due to outliers close to the 90-student cut-off; when we replicate the results using 1999 data, the point estimates and standard errors around the second cut-off are in line with those around the other cut-offs.

${ }^{34}$ In other words, the point estimates could be replicated by dividing the difference in average test scores between the schools above and below the cut-off within each band, by the difference in their respective average class sizes.

${ }^{35}$ In this case dummies for whether enrollments are above the three cut-offs, $1\{x>45\}, 1\{x>90\}$, and $1\{x>$ $135\}$, as well as three sample-specific intercepts serve as instruments; see van der Klaauw (2002).

${ }^{36}$ Note that clustering by enrollment level, as suggested by Lee and Card (forthcoming), lowers significance levels.

${ }^{37}$ Similar stacking occurs if $1^{\text {st }}$ or $8^{\text {th }}$ grade data are used.
} 
the cap. In short, Figure 7 provides a clear illustration of what McCrary (forthcoming) terms manipulation of the running variable - enrollment in this case.

Recall also that the model predicts that higher-income households on average sort into higher- $\lambda$ schools. If so, then the stacking will generate discontinuities in the relationship between enrollment and student characteristics close to the cut-off points, violating the smoothness assumptions underlying the RD approach. Again, Figure 3 illustrates the intuition: because of the stacking, the average value of $\lambda$ among schools at the cap is strictly less than the average value just above the cap; since average household income is strictly monotonically increasing in $\lambda$ (see the discussion in Section 3.4 above), the stacking generates discontinuous changes in household income at the class-size cut-offs. ${ }^{38}$

Panel A of Figure 8 presents enrollment cell means of household income, along with the fitted values of a locally weighted regression calculated within each enrollment segment. There is visual evidence that income changes discontinuously around the first cut-off-schools just to the right contain students who come from wealthier households. Panel B shows, not surprisingly, that they also have students with higher average mothers' schooling — as much as a full year. While jumps at the subsequent cut-off points are less evident, the clear discontinuities at the first one (which provides the bulk of observations, as shown in Figure 7) are sufficient to cast doubt on the RD approach in this context.

Columns 1-3 of Table 5 present regressions of household characteristics on the piecewise linear spline in enrollment and indicator variables for the class-size cut-offs. The results are consistent with the visual evidence from Figure 8. In particular, they confirm that mothers' schooling, fathers' schooling and income display substantial and statistically significant jumps at the first enrollment cut-off; the coefficients for subsequent cut-offs are positive but not significant. This is further evidence that the continuity assumption on the function $f\left(X_{i}\right)$ in (31a) — which is presumed to capture the effect of all variables that vary with enrollment except class size - is violated.

For another indication that something is amiss in the RD design, consider the sensitivity of the estimates of the class-size effect to the inclusion of socioeconomic controls. If the RD approach were valid in this context, then including socioeconomic controls in (31a)-(31b) would

\footnotetext{
${ }^{38}$ It is worth emphasizing that stacking alone may not violate the RD assumptions in our context. If student performance depended only on class size and not directly on $\lambda$, and there were no sorting, then the students on one side of the class-size cut-off would still serve as a valid control group for those on the other side. The violation of the RD assumptions arises from the interaction of the stacking and the endogenous sorting of households.
} 
have little effect on the estimate of $\gamma$. If the conditional means of the controls with respect to enrollment were continuous, then the component of each control that varied with enrollment would be captured by $k\left(X_{i}\right)$ and $f\left(X_{i}\right)$, and the component that was orthogonal to enrollment would also be orthogonal to the instrument. In fact, Columns 4-5 of Table 5 show that the IV estimates from Columns 4-5 of Table 3 are sensitive to the inclusion of socioeconomic controls. The coefficient on class size for the math-score specification drops in magnitude from -0.7 and significant (Table 3, Column 4) to -0.1 and insignificant (Table 5, Column 4) with the inclusion of the controls. For the language-score specification, the drop is from -0.6 to -0.1 . The coefficients on mothers' schooling and income are strongly significant in the test-score regressions; fathers' schooling is significant at the 10 percent level in the math-score specification. ${ }^{39}$ This is clear evidence that the exclusion restriction required for the IV estimates in Table 3 is invalid: the cut-off dummies used as instruments are correlated with household characteristics that are omitted from the Table 3 specification, and those characteristics are in turn correlated with the test-score outcomes.

Finally, we explore to extent to which the observed discontinuities in the treatment and outcome variables, and in other covariates, are robust to more flexible specifications of $k\left(X_{i}\right)$ and $f\left(X_{i}\right)$ in (31a)-(31b). While the literature has not produced a consensus on the correct specification of these functions, ${ }^{40}$ two practical guidelines for credible RD estimation seem uncontroversial. First, there should not be evidence of discontinuities in relevant co-variates at the cut-offs using the same specification of $f\left(X_{i}\right)$ used in the outcome equation (31a), as for instance we found in Columns 1-3 of Table 5. Second, it is worrisome if the results, either for the estimates of $\gamma$ or for the absence of discontinuities in other co-variates, are not robust to the choice of functional form. To investigate this, Table 6 presents reduced-form regressions analogous to those in columns 1-3 of Tables 3 and 5, using higher order specifications of the piecewise control function, as in van der Klaauw (2002). ${ }^{41}$ Note that the first stage (Panel A) is not robust to the addition of more flexible controls - the estimated declines in class size become small or even positive at some cut-offs. This is somewhat surprising given the apparent strength of the first stage observed in

\footnotetext{
${ }^{39}$ These results are qualitatively similar if we use the predicted class size in equation (30) as an instrument for class size in place of the piecewise linear spline. Additionally, although we omit the exercise for the sake of space, we note that the simple within-band IV results in Table 4 are similarly sensitive to the addition of controls for socioeconomic status (results available from the authors).

${ }^{40}$ In their very useful review of practical issues in implementing RD designs, for instance, Imbens and Lemieux (forthcoming) do not make a specific recommendation.

${ }^{41}$ For the sake of space we only report the coefficients on the first two cut-off indicators.
} 
Figure $5 .{ }^{42}$ But more importantly for our story, note that the discontinuous jumps in test scores and socioeconomic status (panels B-F) are robust and, if anything, grow stronger as one moves to the right in the table. In short, Table 6 reaffirms that sorting across the cut-offs appears too strong to allow for reliable implementation of an RD approach.

Lee and Card (forthcoming) propose an additional practical procedure to guide the choice of polynomial for $f\left(X_{i}\right)$ in the outcome equation in a context such as ours in which the running variable is discrete. The test is based on a goodness-of-fit statistic for a "restricted" low-order polynomial specification relative to an "unrestricted" model with a dummy for each value of the discrete running variable. This is not a definitive test-Lee and Card note that rejection of a given polynomial does not necessarily imply that the corresponding estimate of $\gamma$ is inconsistentbut our confidence in a chosen polynomial specification increases if it cannot be rejected by this Lee-Card test. For the outcome equation (31a) in our case, the test does not reject any of the specifications in columns 1-4 of Table 6 . This is consistent with the finding that adding higher-order polynomial terms does not eliminate the discontinuities in the outcome variables and co-variates in Panels B-F of Table 6.

To summarize, our results provide a concrete illustration of Lee's (forthcoming) observation that "economic behavior can corrupt the RD design." It is worth emphasizing that our results apply to settings in which for-profit schools can set prices and directly influence their enrollments, and in which households enjoy substantial freedom to sort between schools; we have no reason to believe that they extend to public-school contexts typically studied. For instance, Angrist and Lavy (1999) point out that in the Israeli public school context they analyze, pupils are required to attend their neighborhood schools, and schools in turn must accept applicants. ${ }^{43}$ Further, migration and immigration may render it difficult for schools to predict enrollments, and private participation is limited to orthodox schools. ${ }^{44}$

\footnotetext{
${ }^{42}$ We have verified that other years and grades of the administrative enrollment data produce similar results.

${ }^{43}$ Similarly, in some exercises Urquiola (2006) considers Bolivian schools in rural towns in which school choice is likely to be very limited.

${ }^{44}$ The observation that Israeli institutions prevent strategic behavior of the kind we emphasize in this paper is consistent with the finding of Angrist and Lavy (1999) that, controlling for secular enrollment effects, adding controls for the proportion of students with low socioeconomic backgrounds does not affect their key estimates. For an alternative approach to checking for discontinuities in co-variates at discontinuities, see McEwan and Shapiro (forthcoming).
} 


\section{Conclusion}

The model developed in this paper offers an explanation for two distinct empirical patterns observed in the Chilean data. First, there is an inverted-U cross-sectional relationship between class size and household income, which is likely to bias non-experimental estimates of the effect of class size. Second, schools' enrollments tend to stack at multiples of the class-size cap, which, in conjunction with the sorting of households into schools of different quality, generates discontinuities in household characteristics at these points. These in turn violate the assumptions required for regression-discontinuity analyses of class size. The fact that a single, relatively parsimonious model can account for these two distinct phenomena suggests that it is a useful way to organize our thinking about class size and sorting in liberalized education markets. Our findings recommend caution in interpreting cross-sectional and RD estimates of the effect of class size in such settings, and underline the value of randomized experiments to estimate class-size effects in contexts where schools are free to set prices and/or turn away students, and households are free to sort between schools. $^{45}$

Our results also recommend caution more broadly in the application and interpretation of RD designs. It has become increasingly common to use discontinuities in the application of regulations to estimate causal effects of those regulations. But in contexts where economic agents interact freely in markets, such discontinuities are likely to generate discontinuities along more than one dimension, undermining the RD approach. This general observation has been made before, by Lee (forthcoming) and others. This paper has sought to provide a concrete illustration of such behavior, in a setting with heterogeneity and sorting on two sides of an important market.

\section{References}

Altonji, J. G., C. Huang, and C. R. Taber (2005): "Estimating the Cream Skimming Effect of Private School Vouchers on Public School Students," Unpub. paper, Northwestern University.

Anderson, S., And A. de Palma (2001): "Product Diversity in Asymmetric Oligopoly: Is the Quality of Consumer Goods Too Low?," Journal of Industrial Economics, 49(2), 113-135.

Anderson, S., A. de Palma, And J.-F. Thisse (1992): Discrete-Choice Theory of Product Differentiation. MIT Press, Cambridge, MA.

\footnotetext{
${ }^{45}$ Banerjee, Cole, Duflo, and Linden (forthcoming) present randomized evaluations of two programs to increase teacher attention per student in India.
} 
Angrist, J., And A. Krueger (1999): "Empirical Strategies in Labor Economics," in Handbook of Labor Economics, ed. by O. Ashenfelter, and D. Card, vol. 3A. Elsevier Science.

Angrist, J. D., And V. Lavy (1999): "Using Maimonides' Rule to Estimate the Effect of Class Size on Scholastic Achievement," Quarterly Journal of Economics, 114(2), 533-575.

Asadullah, M. N. (2005): "The Effect of Class Size on Student Achievement: Evidence from Bangladesh," Applied Economics Letters, 12(4), 217 - 221.

Banerjee, A., S. Cole, E. Duflo, and L. Linden (forthcoming): "Remedying Education: Evidence from Two Randomized Experiments in India," Forthcoming in Quarterly Journal of Economics.

Bartle, R. G. (1976): The Elements of Real Analysis. John Wiley \& Sons, New York, 2nd edition edn.

Bayer, P., R. McMillan, and K. Rueben (2004): "An Equilibrium Model of Sorting in an Urban Housing Market," NBER Working Paper \# 10865.

Bressoux, P., F. Kramarz, and C. Prost (2005): "Teachers' Training, Class Size and Students' Outcomes: Evidence from Third Grade Classes in France," Unpub. paper, CREST.

Browning, M., and E. Heinesen (2003): "Class Size, Teacher Hours and Educational Attainment," Centre for Applied Microeconometrics Working Paper 2003-15, Institute of Economics, University of Copenhagen.

Caucutt, E. M. (2002): "Educational Vouchers When There are Peer Group Effects: Size Matters," International Economic Review, 43(1), 195 - 222.

Clotfelter, C. T. (1999): "Public School Segregation in Metropolitan Areas," Land Economics, 75(4), $487-504$.

Dixit, A. K. (1976): Optimization in Economic Theory. Oxford University Press, Oxford, UK.

Dobbelsteen, S., J. Levin, And H. Oosterbeek (2002): "The Causal Effect of Class Size on Scholastic Achievement: Distinguishing the Pure Class Size Effect from the Effect of Changes in Class Composition," Oxford Bulletin of Economics and Statistics, 64(1), 17-38.

Elacqua, G. (2005): "How Do For-Profit Schools Respond to Voucher Funding? Evidence from Chile," Occasional Paper, National Center for Study of Privatization in Education, Teachers College, Columbia University.

Epple, D., D. Figlio, And R. Romano (2002): "Competition Between Private and Public Schools: Testing Stratification and Pricing Predictions," Unpub. paper, University of Florida.

Epple, D., And R. Romano (1998): "Competition Between Private and Public Schools, Vouchers, and Peer Group Effects," American Economic Review, 88(1), 33-62.

- (2002): "Education Vouchers and Cream Skimming," NBER Working Paper \#9354.

Epple, D., R. Romano, and H. Sieg (2006): "Admission, Tuition, and Financial Aid Policies in the Market for Higher Education," Econometrica, 74(4), 885 - 928.

Ferreyra, M. M. (2007): "Estimating the Effects of Private School Vouchers in Multi-District Economies," American Economic Review, 97(3), 789-817.

Gabszewicz, J. J., And J.-F. Thisse (1979): "Price Competition, Quality, and Income Disparities," Journal of Economic Theory, 20, 340-359.

Hahn, J., P. Todd, And W. van Der KlaAuw (2001): "Identification and Estimation of Treatment Effects with a Regression-Discontinuity Design," Econometrica, 69(1), 201-209.

HanusheK, E. A. (1995): "Interpreting Recent Research on Schooling in Developing Countries," World Bank Research Observer, 10, 227-246.

— (2003): "The Failure of Input-Based Schooling Policies," Economic Journal, 113(485), F64-F98. 
Hoxby, C. M. (2000): "The Effects of Class Size on Student Achievement: New Evidence from Population Variation," Quarterly Journal of Economics, 115(4), 1239-1285.

Hsieh, C.-T., And M. Urquiola (2006): "The Effects of Generalized School Choice on Achievement and Stratification: Evidence from Chile's School Voucher Program," Journal of Public Economics, 90, $1477-1503$.

Imbens, G., And T. Lemieux (forthcoming): "Regression Discontinuity Designs: A Guide to Practice," Forthcoming in Journal of Econometrics.

Jakubowski, M., And P. SAKowski (2005): "Quasi-Experimental Estimates of Class Size Effect in Primary Schools in Poland," Unpub. paper, Warsaw University, Faculty of Economics.

Kremer, M. R. (1995): "Research on Schooling: What We Know and What We Don't: A Comment," World Bank Research Observer, 10(2), 247-254.

Krueger, A. B. (2003): "Economic Considerations and Class Size," Economic Journal, 113(485), F34-63.

LAZEAR, E. P. (2001): "Educational Production," Quarterly Journal of Economics, 116(3), 777-803.

LEE, D. S. (forthcoming): "Randomized Experiments from Non-Random Selection in U.S. House Elections," Forthcoming in Journal of Econometrics.

LEE, D. S., AND D. CARD (forthcoming): "Regression Discontinuity Inference with Specification Error," Forthcoming in Journal of Econometrics.

Manski, C. (1992): "Educational Choice (Vouchers) and Social Mobility," Economics of Education Review, 11(4), 351-369.

MCCRARY, J. (forthcoming): "Manipulation of the Running Variable in the Regression Discontinuity Design: A Density Test," Forthcoming in Journal of Econometrics.

McEwan, P., And J. Shapiro (forthcoming): "The Benefits of Delayed Primary School Enrollment: Discontinuity Estimates Using Exact Birth Dates," Forthcoming in Journal of Human Resources.

McFadden, D. (1974): "Conditional Logit Analysis of Qualitative Choice Behavior," in Frontiers in Econometrics, ed. by P. Zarembka, pp. 105-142. Academic Press, New York.

Mizala, A., And P. Romaguera (2002): "Equity and Educational Performance," Economía, 2(2), 219262.

Mussa, M., And S. Rosen (1978): "Monopoly and Product Quality," Journal of Economic Theory, 18, 301-317, a.

Nechyba, T. J. (2003): “Centralization, Fiscal Federalism, and Private School Attendance," International Economic Review, 44(1), 179-204.

Nesheim, L. (2002): "Equilibrium Sorting of Heterogeneous Consumers Across Locations: Theory and Empirical Implications," CEMMAP Working Paper CWP08/02, University College London.

Piketty, T., And M. Valdenaire (2006): "L'Impact de la Taille des Classes sur la Réussite Scolaire Dans les Écoles, Collèges et Lycées Fran cais [The Impact of Class Size on Student Success in French Primary and Secondary Schools]," Les Dossiers, Ministère de l'Éducation Nationale, no. 173.

Rothstein, J. (2006): "Good Principals or Good Peers? Parental Valuation of School Characteristics, Tiebout Equilibrium, and the Effects of Inter-District Competition," American Economic Review, 96(4), $1333-1350$.

Shadish, W. R., T. D. Cook, and D. T. Campbell (2002): Experimental and Quasi-Experimental Designs for Generalized Causal Inference. Boston.

Shaked, A., And J. Sutton (1982): "Relaxing Price Competition through Product Differentiation," Review of Economic Studies, 49, 3-13.

Thistlewaite, D., And D. Campbell (1960): "Regression Discontinuity Analysis: An Alternative to 
the Ex-Post Facto Experiment," Journal of Educational Psychology, 51, 309-317.

Urquiola, M. (2005): "Does School Choice Lead to Sorting? Evidence from Tiebout Variation," American Economic Review, 95(4), 1310-1326.

(2006): "Identifying Class Size Effects in Developing Countries: Evidence from Rural Schools in Bolivia," Review of Economics and Statistics, 88(1).

VAN DER KlaAuw, W. (2002): "Estimating the Effect of Financial Aid Offers on College Enrollment: A Regression Discontinuity Approach," International Economic Review, 43(4), 1249-1287.

Verhoogen, E. A. (2007): "Trade, Quality Upgrading and Wage Inequality in the Mexican Manufacturing Sector," CEPR discussion paper no. 6385, July.

Wössmann, L. (2005): "Educational Production in Europe," Economic Policy, (43), 445 - 493. 


\section{A Theory Appendix}

In this appendix, to avoid clutter, we do not write explicitly the dependence of $x, n$ and $p$ on $\lambda$, of $q(\cdot)$ on $x, n$ and $\lambda$, or of $d(\cdot)$ and $\Theta(\cdot)$ on $p$ and $q$, but this dependence should be understood. As above, asterisks indicate equilibrium values.

\section{A.1 Case 1: Divisible Classrooms}

To solve the school's optimization problem in this case, form the Lagrangian from (9), where the constraints are (12) and (11):

$$
\mathcal{L}(p, x, n ; \lambda)=(p-c+\tau) x-n F_{c}-F_{s}-\phi_{1}(x-d)-\phi_{2}\left(\frac{x}{n}-45\right)
$$

The first-order conditions are:

$$
\begin{aligned}
\frac{\partial \mathcal{L}}{\partial p} & =x+\phi_{1}\left(-\frac{d}{\mu}\right)=0 \\
\frac{\partial \mathcal{L}}{\partial n} & =-F_{c}+\phi_{1} \int_{\underline{\theta}}^{\bar{\theta}} \frac{\partial s(\lambda \mid \theta, q, p)}{\partial n} M g(\theta) \mathrm{d} \theta+\phi_{2}\left(\frac{x}{n^{2}}\right) \\
& =-F_{c}+\phi_{1}\left(\frac{\lambda \Theta d}{\mu n}\right)+\phi_{2}\left(\frac{x}{n^{2}}\right)=0 \\
\frac{\partial \mathcal{L}}{\partial x} & =p-c+\tau-\phi_{1}\left(1-\int_{\underline{\theta}}^{\bar{\theta}} \frac{\partial s(\lambda \mid \theta, q, p)}{\partial x} g(\theta) \mathrm{d} \theta\right)-\phi_{2}\left(\frac{1}{n}\right) \\
& =p-c+\tau-\phi_{1}\left(1+\frac{\lambda \Theta d}{\mu x}\right)-\phi_{2}\left(\frac{1}{n}\right)=0 \\
\frac{\partial \mathcal{L}}{\partial \phi_{1}} & \geq 0, \phi_{1} \geq 0, \text { and } \phi_{1} \frac{\partial \mathcal{L}}{\partial \phi_{1}}=0 \\
\frac{\partial \mathcal{L}}{\partial \phi_{2}} & \geq 0, \phi_{2} \geq 0, \text { and } \phi_{2} \frac{\partial \mathcal{L}}{\partial \phi_{2}}=0
\end{aligned}
$$

where $s(\lambda \mid \theta, q, p)$ is given by (2). The interchanging of the partial derivatives and the integrals is justified by a standard property of integrals (see e.g. Bartle (1976, Theorem 31.7, p. 245)) and the continuity of $s(\lambda \mid \theta, q, p)$ and its partial derivatives.

Suppose $\phi_{1}=0$ and $\frac{\partial \mathcal{L}}{\partial \phi_{1}}>0$, i.e. the demand constraint is not binding. Then (33a) implies $x=0$, and (33b) in turn implies $F_{c}=0$, which is false. Hence if there is a solution it must be that $\frac{\partial \mathcal{L}}{\partial \phi_{1}}=0$ and the demand constraint is binding: $x=d$. It follows from (33a) that $\phi_{1}=\mu$. We then have two sub-cases.

\section{A.1.1 Sub-Case 1.1: Class-Size Cap Non-Binding}

In this sub-case, the class size cap is non-binding: $\phi_{2}=0$ and $\frac{\partial \mathcal{L}}{\partial \phi_{2}} \geq 0$. By (33b), $\frac{x}{n}=\frac{F_{c}}{\lambda \Theta}$ and $\frac{\partial \mathcal{L}}{\partial \phi_{2}} \geq 0$ implies $\lambda \Theta \geq \frac{F_{c}}{45}$. Simple algebra then yields (13a)-(13c). 
To check the second-order conditions, form the bordered Hessian:

$$
H \equiv\left(\begin{array}{cccc}
0 & \frac{\partial h}{\partial p} & \frac{\partial h}{\partial n} & \frac{\partial h}{\partial x} \\
\frac{\partial h}{\partial p} & \frac{\partial^{2} \mathcal{L}}{\partial p^{2}} & \frac{\partial^{2} \mathcal{L}}{\partial n \partial p} & \frac{\partial^{2} \mathcal{L}}{\partial x \partial p} \\
\frac{\partial h}{\partial n} & \frac{\partial^{2} \mathcal{L}}{\partial p \partial n} & \frac{\partial^{2} \mathcal{L}}{\partial n^{2}} & \frac{\partial^{2} \mathcal{L}}{\partial x \partial n} \\
\frac{\partial h}{\partial x} & \frac{\partial^{2} \mathcal{L}}{\partial p \partial x} & \frac{\partial^{2} \mathcal{L}}{\partial n \partial x} & \frac{\partial^{2} \mathcal{L}}{\partial x^{2}}
\end{array}\right)
$$

where $h(p, n, x ; \lambda) \equiv x-d$. It is then straightforward (if tedious) to show that the last two leading principal minors alternate in sign with the last one negative (and hence that the Hessian of $\mathcal{L}$ is negative definite on the constraint set) if and only if (14) holds. Rewriting (14),

$$
\int_{\underline{\theta}}^{\bar{\theta}} \theta\left[\frac{s\left(\lambda \mid \theta, q^{*}, p^{*}\right) g(\theta)}{s\left(q^{*}, p^{*}\right)}\right] \mathrm{d} \theta>\int_{\underline{\theta}}^{\bar{\theta}}\left(\frac{\lambda \theta}{\mu}\right) \theta\left[\frac{s\left(\lambda \mid \theta, q^{*}, p^{*}\right) g(\theta)}{s\left(q^{*}, p^{*}\right)}\right] \mathrm{d} \theta-\frac{\lambda \Theta^{* 2}}{\mu}
$$

Under assumption (7), $\frac{\lambda \theta}{\mu}<1$ for all values of $\lambda$ and $\theta$. Hence the left-hand-side term is greater than the first term on the right-hand side. Since the second term on the right-hand side is negative, it follows that the solution to the first-order conditions given is a local constrained maximum. Moreover, the negative-definiteness of $\mathcal{L}$ on the constraint set holds for all $p, n$ and all $x>0$, hence the local maximum is a unique global maximum of the constrained optimization problem.

Rewrite (13a)-(13c), together with (5), noting that $\phi=\mu$ and $x=d$ :

$$
\begin{aligned}
& G_{1}=p^{*}-\left(\mu+c-\tau+\lambda \Theta^{*}\right)=0 \\
& G_{2}=x^{*}-\int_{\underline{\theta}}^{\bar{\theta}} s\left(\lambda \mid \theta, q^{*}, p^{*}\right) M g(\theta) \mathrm{d} \theta=0 \\
& G_{3} \equiv \Theta^{*}-\int_{\underline{\theta}}^{\bar{\theta}} \theta\left[\frac{s\left(\lambda \mid \theta, q^{*}, p^{*}\right) g(\theta)}{s\left(q^{*}, p^{*}\right)}\right] \mathrm{d} \theta=0 \\
& G_{4}=-F_{c}+\frac{\lambda \Theta^{*} x^{*}}{n^{*}}=0
\end{aligned}
$$

It is convenient to define $z^{*}=\frac{x^{*}}{n^{*}}$ (class size) and analyze (34a)-(34d) as a set of four equations with four endogenous variables, $p^{*}, x^{*}, \Theta$, and $z^{*}$, and one exogenous variable, $\lambda$. Let $J$ be the Jacobian:

$$
J \equiv\left(\begin{array}{llll}
\frac{\partial G_{1}}{\partial p^{*}} & \frac{\partial G_{1}}{\partial x^{*}} & \frac{\partial G_{1}}{\partial z^{*}} & \frac{\partial G_{1}}{\partial \Theta^{*}} \\
\frac{\partial G_{2}}{\partial p^{*}} & \frac{\partial G_{2}}{\partial x^{*}} & \frac{\partial G_{2}}{\partial z^{*}} & \frac{\partial G_{2}}{\partial \Theta^{*}} \\
\frac{\partial G_{3}}{\partial p^{*}} & \frac{\partial G_{3}}{\partial x^{*}} & \frac{\partial G_{3}}{\partial z^{*}} & \frac{\partial G_{3}}{\partial \Theta^{*}} \\
\frac{\partial G_{4}}{\partial p^{*}} & \frac{\partial G_{4}}{\partial x^{*}} & \frac{\partial G_{4}}{\partial z^{*}} & \frac{\partial G_{4}}{\partial \Theta^{*}}
\end{array}\right)
$$

By the implicit function theorem:

$$
\left(\begin{array}{l}
\frac{\partial p^{*}}{\partial \lambda} \\
\frac{\partial x^{*}}{\partial \lambda} \\
\frac{\partial z^{*}}{\partial \lambda} \\
\frac{\partial \Theta^{*}}{\partial \lambda}
\end{array}\right)=-J^{-1}\left(\begin{array}{c}
\frac{\partial G_{1}}{\partial \lambda} \\
\frac{\partial G_{2}}{\partial \lambda} \\
\frac{\partial G_{3}}{\partial \lambda} \\
\frac{\partial G_{4}}{\partial \lambda}
\end{array}\right)
$$


It is straightforward to show that:

$$
\operatorname{det} J=-\frac{\Psi}{\Theta^{*}}<0
$$

since $\Psi>0$ (refer to (14)). Simplifying (35), we have:

$$
\left(\begin{array}{c}
\frac{\partial p^{*}}{\partial \lambda} \\
\frac{\partial x^{*}}{\partial \lambda} \\
\frac{\partial z^{*}}{\partial \lambda} \\
\frac{\partial \Theta^{*}}{\partial \lambda}
\end{array}\right)=\left(\begin{array}{c}
\frac{\Theta^{*}}{\Psi}\left[\Theta^{*}+\frac{\lambda}{\mu} \ln \left(\frac{T}{z^{*}}\right) \sigma_{\theta \mid \lambda}^{2}\right] \\
\frac{x^{*} \Theta^{*}}{\mu} \ln \left(\frac{T}{z^{*}}\right) \\
-\frac{z^{*}}{\lambda \Psi}\left[\frac{\lambda}{\mu} \ln \left(\frac{T}{z^{*}}\right) \sigma_{\theta \mid \lambda}^{2}+\Theta^{*}\right] \\
\frac{\Theta^{*} \sigma_{\theta \mid \lambda}^{2}}{\mu \Psi}\left[\ln \left(\frac{T}{z^{*}}\right)+1\right]
\end{array}\right)
$$

at the optimum.

In the definition of $\sigma_{\theta \mid \lambda}^{2}$ in (15), the fact that the double-exponential distribution yields a non-zero probability that any given household will choose any given school implies that the term in brackets is non-zero for all $\theta$. Hence as long as $\theta \neq \Theta^{*}$ for some $\theta$, which follows from the assumption that $\theta$ has positive support over $(\underline{\theta}, \bar{\theta})$, we have:

$$
\sigma_{\theta \mid \lambda}^{2}>0
$$

The results (16a), (16b), (16d) and (16e) follow from (14), (37) and (38). Finally, we have:

$$
\frac{\partial n^{*}}{\partial \lambda}=\frac{\partial}{\partial \lambda}\left(\frac{x^{*}}{z^{*}}\right)=\frac{1}{z^{*}} \frac{\partial x^{*}}{\partial \lambda}-\frac{x^{*}}{z^{* 2}} \frac{\partial z^{*}}{\partial \lambda}>0
$$

where the inequality follows from (16b) and (16e). This gives (16c).

\section{A.1.2 Sub-Case 1.2: Class-Size Cap Binding}

In this sub-case, the class-size cap is binding: $\phi_{2} \geq 0$ and $\frac{\partial \mathcal{L}}{\partial \phi_{2}}=0$ (that is, $\frac{x}{n}=45$ ). By (33b) and the facts that $x=d$ and $\phi_{1}=\mu$, we have $\frac{\phi_{2}}{n}=\frac{F}{45}-\lambda \Theta$. The fact that $\phi_{2} \geq 0$ implies $\lambda \Theta \leq \frac{F}{45}$. Algebra yields (17a)-(17c).

To verify the second-order conditions, the bordered Hessian is:

$$
H \equiv\left(\begin{array}{ccccc}
0 & 0 & \frac{\partial h_{1}}{\partial p} & \frac{\partial h_{1}}{\partial n} & \frac{\partial h_{1}}{\partial x} \\
0 & 0 & \frac{\partial h_{2}}{\partial p} & \frac{\partial h_{2}}{\partial n} & \frac{\partial h_{2}}{\partial x} \\
\frac{\partial h_{1}}{\partial p} & \frac{\partial h_{2}}{\partial p} & \frac{\partial^{2} \mathcal{L}}{\partial p^{2}} & \frac{\partial^{2} \mathcal{L}}{\partial n \partial p} & \frac{\partial^{2} \mathcal{L}}{\partial x \partial p} \\
\frac{\partial h_{1}}{\partial n} & \frac{\partial h_{2}}{\partial n} & \frac{\partial^{2} \mathcal{L}}{\partial p \partial} & \frac{\partial^{2} \mathcal{L}}{\partial n^{2}} & \frac{\partial^{2} \mathcal{L}}{\partial x \partial n} \\
\frac{\partial h_{1}}{\partial x} & \frac{\partial h_{2}}{\partial x} & \frac{\partial^{2} \mathcal{L}}{\partial p \partial x} & \frac{\partial^{2} \mathcal{L}}{\partial n \partial x} & \frac{\partial^{2} \mathcal{L}}{\partial x^{2}}
\end{array}\right)
$$

where $\mathcal{L}$ is given in $(32), h_{1}(p, n, x, \lambda) \equiv x-d$ and $h_{2}(p, n, x, \lambda) \equiv \frac{x}{n}-45$. It is straightforward to verify that $\operatorname{det} H=-\frac{x^{3}}{\mu n^{4}}<0$ at the optimum, and hence that the second-order conditions for a maximum are satisfied. 
To analyze the slopes with respect to $\lambda$ in this sub-case, rewrite (17a)-(17c) with (5) as:

$$
\begin{aligned}
& G_{1}=p^{*}-\left(c-\tau+\mu+\frac{F_{c}}{45}\right)=0 \\
& G_{2}=x^{*}-\int_{\underline{\theta}}^{\bar{\theta}} s\left(\lambda \mid \theta, q^{*}, p^{*}\right) M g(\theta) \mathrm{d} \theta=0 \\
& G_{3} \equiv \Theta^{*}-\int_{\underline{\theta}}^{\bar{\theta}} \theta\left[\frac{s\left(\lambda \mid \theta, q^{*}, p^{*}\right) g(\theta)}{s\left(q^{*}, p^{*}\right)}\right] \mathrm{d} \theta=0 \\
& G_{4}=n^{*}-\frac{x^{*}}{45}=0
\end{aligned}
$$

Applying the implicit function theorem (as in (35)) to (40a)-(40d), we have:

$$
\left(\begin{array}{c}
\frac{\partial p^{*}}{\partial \lambda} \\
\frac{\partial x^{*}}{\partial \lambda} \\
\frac{\partial n^{*}}{\partial \lambda} \\
\frac{\partial \Theta^{*}}{\partial \lambda}
\end{array}\right)=\frac{1}{\mu} \ln \left(\frac{T}{45}\right)\left(\begin{array}{c}
0 \\
x^{*} \Theta^{*} \\
\frac{x^{*} \Theta^{*}}{45} \\
\sigma_{\theta \mid \lambda}^{2}
\end{array}\right)
$$

which in turn implies (18a)-(18e).

The fact that $\frac{\partial \Theta^{*}}{\partial \lambda}>0$ in both sub-cases implies that $\lambda \Theta^{*}$ is monotonically increasing in $\lambda$ and guarantees that there is at most one critical value of $\lambda$, call it $\alpha$, at which (19) holds. The results for the first sub-case apply for $\lambda \geq \alpha$ and the results for the second sub-case apply for $\lambda<\alpha$.

\section{A.2 Case 2: Indivisible Classrooms}

The Lagrangian in this case is the same as (32), but $n$ is now interpreted as a parameter:

$$
\mathcal{L}(p, x ; n, \lambda)=(p-c+\tau) x-n F_{c}-F_{s}-\phi_{1}(x-d)-\phi_{2}\left(\frac{x}{n}-45\right)
$$

The first-order conditions are:

$$
\begin{aligned}
\frac{\partial \mathcal{L}}{\partial p} & =x-\phi_{1}\left(\frac{d}{\mu}\right)=0 \\
\frac{\partial \mathcal{L}}{\partial x} & =p-c+\tau-\phi_{1}\left(1+\frac{\lambda \Theta d}{\mu x}\right)-\phi_{2}\left(\frac{1}{n}\right)=0 \\
\frac{\partial \mathcal{L}}{\partial \phi_{1}} & \geq 0, \phi_{1} \geq 0, \text { and } \phi_{1} \frac{\partial \mathcal{L}}{\partial \phi_{1}}=0 \\
\frac{\partial \mathcal{L}}{\partial \phi_{2}} & \geq 0, \phi_{2} \geq 0, \text { and } \phi_{2} \frac{\partial \mathcal{L}}{\partial \phi_{2}}=0
\end{aligned}
$$

We can quickly rule out the possibility that the demand constraint is not binding:

1. If neither the demand constraint nor the class-size cap is binding $\left(\phi_{1}=0, \frac{\partial \mathcal{L}}{\partial \phi_{1}} \geq 0, \phi_{2}=0\right.$ and $\frac{\partial \mathcal{L}}{\partial \phi_{2}} \geq 0$ ) then by (43a), $x=0$ and by (43b), $p=c-\tau$. It is straightforward to verify that the second-order conditions are not satisfied in this sub-case.

2. If the demand constraint is not binding but the class-size cap is binding $\left(\phi_{1}=0, \frac{\partial \mathcal{L}}{\partial \phi_{1}} \geq 0\right.$, 
$\phi_{2} \geq 0$ and $\left.\frac{\partial \mathcal{L}}{\partial \phi_{2}}=0\right)$ then by (43a), we have $x=0$. This violates the class-size constraint $\left(\frac{x}{n}=45\right)$; hence there is no solution in this case.

There are then two sub-cases to be considered.

\section{A.2.1 Sub-Case 2.1: Class-Size Cap Non-Binding}

In this sub-case, the demand constraint is binding and the class-size cap is non-binding: $\phi_{1} \geq 0$, $\frac{\partial \mathcal{L}}{\partial \phi_{1}}=0, \phi_{2}=0, \frac{\partial \mathcal{L}}{\partial \phi_{2}} \geq 0$. Equations (20a)-(20b) follow immediately from (43a)-(43b).

The second-order conditions can be verified by evaluating the determinant of the bordered Hessian ( $3 \times 3$ in this case). The determinant is positive, and the second-order conditions are satisfied, if condition (14) is satisfied. This condition is guaranteed by (7). We again have that the Hessian of the profit function is negative definite on the constraint set, and hence that the solution given by (20a)-(20b) is a global maximum.

Rewrite (20a)-(20b), together with (5):

$$
\begin{aligned}
G_{1} & =p^{*}-\left[\mu+c-\tau+\lambda \Theta^{*}\right]=0 \\
G_{2} & \equiv x^{*}-\int_{\underline{\theta}}^{\bar{\theta}} s\left(\lambda \mid \theta, q^{*}, p^{*}\right) M g(\theta) \mathrm{d} \theta=0 \\
G_{3} & \equiv \Theta^{*}-\int_{\underline{\theta}}^{\bar{\theta}} \theta\left[\frac{s\left(\lambda \mid \theta, q^{*}, p^{*}\right) g(\theta)}{s\left(q^{*}, p^{*}\right)}\right] \mathrm{d} \theta=0
\end{aligned}
$$

Note that these are the same as (34a)-(34c). (The number of classrooms is now treated as a parameter, and we no longer have (34d).) Inverting the Jacobian (3x3 in this case) and using the implicit function theorem (as in (35)) applied to (44a)-(44c), we have:

$$
\left(\begin{array}{c}
\frac{\partial p^{*}}{\partial \lambda} \\
\frac{\partial x^{*}}{\partial \lambda} \\
\frac{\partial \Theta^{*}}{\partial \lambda}
\end{array}\right)=\frac{1}{1+\frac{\lambda \Psi}{\mu}}\left(\begin{array}{c}
\Theta^{*}+\frac{\lambda \Theta^{* 2}}{\mu}+\frac{\lambda}{\mu} \ln \left(\frac{n T}{x^{*}}\right) \sigma_{\theta \mid \lambda}^{2} \\
\frac{x^{*}}{\mu}\left[\Psi \ln \left(\frac{n T}{x^{*}}\right)-\Theta^{*}\right] \\
\frac{\sigma_{\theta \mid \lambda}^{2}}{\mu}\left[\frac{\lambda \Theta^{*}}{\mu}+\ln \left(\frac{n T}{x^{*}}\right)\right]
\end{array}\right)
$$

The results (21a),(21b) and (23) follow from (14), (22), (38), and (45).

The condition $\frac{\partial \mathcal{L}}{\partial \phi_{2}} \geq 0$ requires:

$$
45 n \leq \int_{\underline{\theta}}^{\bar{\theta}} \frac{1}{\Omega(\theta)}\left(\frac{T}{45}\right)^{\frac{\theta \lambda}{\mu}} \exp \left(-\frac{c-\tau+\mu+\lambda \Theta^{*}}{\mu}\right) M g(\theta) \mathrm{d} \theta
$$

Taking the exponential term out of the integral and solving for $\lambda \Theta^{*}$, we have:

$$
\lambda \Theta^{*} \leq \mu \ln \Sigma-\mu \ln (45 n)-c+\tau-\mu
$$

where $\Sigma$ is defined as in (25). Setting this inequality to an equality yields (27), which implicitly defines $\beta(n)$, the value of $\lambda$ at which the class-size cap begins to bind. 


\section{A.2.2 Sub-Case 2.2: Class-Size Cap Binding}

In this sub-case, both the demand constraint and class-size cap are binding: $\phi_{1} \geq 0, \frac{\partial \mathcal{L}}{\partial \phi_{1}}=0$, $\phi_{2} \geq 0$ and $\frac{\partial \mathcal{L}}{\partial \phi_{2}}=0$. The two constraints, $x=d$ and $x=45 n$, pin down the values of $p$ and $x$, and the results (24a)-(24b) follow immediately.

The fact that $\frac{\partial x^{*}}{\partial \lambda}=\frac{\partial}{\partial \lambda}\left(\frac{x}{n}\right)=0$ follows immediately. It is straightforward to show that

$$
\begin{aligned}
\frac{\partial p^{*}}{\partial \lambda} & =\Theta^{*} \ln \left(\frac{T}{45}\right)>0 \\
\frac{\partial \Theta^{*}}{\partial \lambda} & =\frac{1}{\mu} \sigma_{\theta \mid \lambda}^{2} \ln \left(\frac{T}{45}\right)>0
\end{aligned}
$$

It remains to establish the set of schools over which the condition $\phi_{2} \geq 0$ is satisfied. The first order conditions imply:

$$
\phi_{2}=n\left\{\mu \ln \Sigma-\mu \ln (45 n)-c+\tau-\mu-\lambda \Theta^{*}\right\}
$$

By the definition of $\beta(n)$ above, if $\lambda=\beta(n)$ then $\phi_{2}=0$. Partially differentiating (47):

$$
\begin{aligned}
\frac{\partial \phi_{2}}{\partial \lambda} & =n\left\{\frac{\mu}{\Sigma} \frac{\partial \Sigma}{\partial \lambda}-\lambda \frac{\partial \Theta^{*}}{\partial \lambda}-\Theta^{*}\right\} \\
& =n\left\{\Psi \ln \left(\frac{T}{45}\right)-\Theta^{*}\right\}>0
\end{aligned}
$$

by assumption (22). Thus $\phi_{2} \geq 0$ for $\lambda \geq \beta(n)$. The first sub-case applies for $\lambda \leq \beta(n)$ and the second applies for $\lambda>\beta(n)$.

Finally, it follows from (45), (46a), and (22) that:

$$
\lim _{\lambda \rightarrow \beta(n)^{-}} \frac{\partial p^{*}}{\partial \lambda}<\lim _{\lambda \rightarrow \beta(n)^{+}} \frac{\partial p^{*}}{\partial \lambda}
$$

That is, the slope of $p^{*}$ with respect to $\lambda$ is steeper to the right of the critical value, in the region where the class-size cap binds.

\section{A.2.3 Proof of Lemma 1}

Our strategy for proof is to begin with a preliminary partition of the set of schools and show that within each subset there are two possible optimal integer choices, and that there is a critical value below which the lower integer is optimal and above which the higher integer is optimal. These new critical values become the basis for the new partition described in the statement of the lemma.

1. For a given integer $k$, let $\delta_{k}$ be the value of $\lambda$ at which the optimal number of classrooms in Case 1, the divisible-classrooms case, is $k$. That is, $\delta_{k} \equiv n^{*-1}(k)$ where $n^{*}(\lambda)$ is defined by (13c) for $\lambda \geq \alpha$ and by (17c) for $\lambda<\alpha$. As noted above, $n^{*}(\lambda)$ is continuous and monotonically increasing in $\lambda$. This implies that $\delta_{k^{\prime}}>\delta_{k}$ if $k^{\prime}>k$ for any positive integers $k, k^{\prime}$. The values $\delta_{k}$ thus form an ordered partition the set of schools. 
2. We now show that within the interval $\lambda \in\left[\delta_{k}, \delta_{k+1}\right)$, the optimal integer number of classrooms is either $k$ or $k+1$.

(a) Define functions for profits under the counterfactual assumptions that the class-size cap never binds and that it always binds. That is, let:

$$
\pi^{*}(n, \lambda)=\pi\left(p^{*}(n, \lambda), x^{*}(n, \lambda), n, \lambda\right)
$$

where $p^{*}(n, \lambda)$ and $x^{*}(n, \lambda)$ are given by (20a) and (20a), the optimal choices when the class-size cap does not bind. Let:

$$
\pi^{* *}(n, \lambda)=\pi\left(p^{*}(n, \lambda), x^{*}(n, \lambda), n, \lambda\right)
$$

where $p^{*}(n, \lambda)$ and $x^{*}(n, \lambda)$ are given by $(24 \mathrm{~b})$ and $(24 \mathrm{a})$, the optimal choices when the class-size cap binds. The definition of $\tilde{\pi}(\cdot)$ in $(28)$ can then be restated:

$$
\tilde{\pi}(n, \lambda)= \begin{cases}\pi^{*}(n, \lambda) & \text { if } \quad \lambda \leq \beta(n) \\ \pi^{* *}(n, \lambda) & \text { if } \quad \lambda>\beta(n)\end{cases}
$$

(b) We now show that $\pi^{*}(n, \lambda), \pi^{* *}(n, \lambda)$ and hence $\widetilde{\pi}(n, \lambda)$ are concave in $n$ for any given $\lambda$ :

i. By the envelope theorem, we have:

$$
\frac{\partial \pi^{*}}{\partial n}=\frac{\partial \mathcal{L}}{\partial n}
$$

where $\mathcal{L}$ is given by (32) and $\frac{\partial \pi^{*}}{\partial n}$ allows $p$ and $x$ to vary (holding $\lambda$ constant) but $\frac{\partial \mathcal{L}}{\partial n}$ holds $p, x$ and $\lambda$ constant. Then by $(33 \mathrm{~b})$ :

$$
\begin{aligned}
\frac{\partial^{2} \pi^{*}}{\partial n^{2}}=\frac{\partial}{\partial n}\left(\frac{\partial \mathcal{L}}{\partial n}\right) & =\frac{\partial}{\partial n}\left(-F_{c}+\frac{\lambda \Theta^{*} x^{*}}{n}\right) \\
& =-\frac{\lambda \Theta^{*} x^{*}}{n^{2}}+\frac{\lambda \Theta^{*}}{n} \frac{\partial x^{*}}{\partial n}+\frac{\lambda x^{*}}{n} \frac{\partial \Theta^{*}}{\partial n}
\end{aligned}
$$

Applying the implicit function theorem (as in (35)) to (44a)-(44c),

$$
\left(\begin{array}{c}
\frac{\partial p^{*}}{\partial n} \\
\frac{\partial x^{*}}{\partial n} \\
\frac{\partial \Theta^{*}}{\partial n}
\end{array}\right)=\frac{\lambda}{\mu+\lambda \Psi}\left(\begin{array}{c}
\frac{\lambda \sigma_{\theta \mid \lambda}^{2}}{n} \\
\frac{x^{*} \Psi}{n} \\
\frac{\sigma_{\theta \mid \lambda}^{2}}{n}
\end{array}\right)
$$

Plugging into (50),

$$
\frac{\partial^{2} \pi^{*}}{\partial n^{2}}=-\frac{\lambda x \Psi}{n^{2}\left(1+\frac{\lambda \Psi}{\mu}\right)}<0
$$

Hence $\pi^{*}(n, \lambda)$ is globally concave in $n$ for all $\lambda$.

ii. Combining (8), (24a) and (24b), and differentiating twice with respect to $n$, we have that $\frac{\partial^{2} \pi^{* *}}{\partial n^{2}}=-\frac{45 \mu}{n}<0$. Hence $\pi^{* *}(n, \lambda)$ is globally concave in $n$ for all $\lambda$ as well. 
iii. Implicitly differentiating (27) with respect to $n$, we have:

$$
\frac{\partial \beta(n)}{\partial n}=\frac{\mu}{n\left(\Psi \ln \left(\frac{T}{45}\right)-\Theta\right)}>0
$$

for all $n$, where the inequality follows from (22). Hence there is a one-to-one mapping between $\beta(n)$ and $n$ for a given $\lambda$. $\beta^{-1}(\lambda)$ is then the value of $n$ at which the class-size cap starts to bind for a given $\lambda$. Note that the cap binds for $n<\beta^{-1}(\lambda)$ and does not bind for $n \geq \beta^{-1}(\lambda)$. The definition of $\tilde{\pi}(\cdot)$ in (48) can then be rewritten:

$$
\widetilde{\pi}(n, \lambda)=\left\{\begin{array}{lll}
\pi^{*}(n, \lambda) & \text { if } & n \geq \beta^{-1}(\lambda) \\
\pi^{* *}(n, \lambda) & \text { if } & n<\beta^{-1}(\lambda)
\end{array}\right.
$$

The function $\pi^{*}(n, \lambda)$ gives the maximized profit for a given $n$ and $\lambda$ under one equality constraint, namely $x=d$. The function $\pi^{* *}(n, \lambda)$ gives the maximized profit for a given $n$ and $\lambda$ under two equality constraints, namely $x=d$ and $\frac{x}{n}=45$. For a given $\lambda$, the two points coincide at the point where the optimal class size is 45 even in the absence of the cap - that is, where $n=\beta^{-1}(\lambda)$-and for all other $n$ the function $\pi^{* *}(n, \lambda)$ lies under $\pi^{*}(n, \lambda)$. A standard result in optimization theory is that (if both functions are continuously differentiable) the two curves are tangent at that point (see e.g. Dixit (1976, Ch. 3)).

Now consider the curvature of the $\tilde{\pi}(n, \lambda)$ function. For $n<\beta^{-1}(\lambda), \frac{\partial \widetilde{\pi}}{\partial n}$ is decreasing in $n$ by the concavity of $\pi^{* *}(n, \lambda)$. For $n \geq \beta^{-1}(\lambda), \frac{\partial \widetilde{\pi}}{\partial n}$ is decreasing in $n$ by the concavity of $\pi^{*}(n, \lambda)$. At $n=\beta^{-1}(\lambda)$ the two curves are tangent and $\frac{\partial \pi^{*}}{\partial n}=\frac{\partial \pi^{* *}}{\partial n}$. It follows that $\frac{\partial \widetilde{\pi}}{\partial n}$ is decreasing in $n$ for all $n$ and all $\lambda$. Hence $\widetilde{\pi}(n, \lambda)$ is globally concave in $n$ for all $\lambda$.

(c) Recall the definition of $n^{*}(\lambda)$, the optimal number of classrooms in the divisibleclassroom case, from step 1 of this proof. Since $n^{*}(\lambda)$ is monotonically increasing in $\lambda, \lambda \in\left[\delta_{k}, \delta_{k+1}\right)$ implies $n^{*}(\lambda) \in[k, k+1)$. From the concavity of $\widetilde{\pi}(n, \lambda)$ it follows that:

$$
\begin{aligned}
\tilde{\pi}(k, \lambda) & >\widetilde{\pi}\left(k^{\prime}, \lambda\right) \forall k^{\prime}<k \\
\tilde{\pi}(k+1, \lambda) & >\tilde{\pi}\left(k^{\prime}, \lambda\right) \forall k^{\prime}>k+1
\end{aligned}
$$

That is, within the interval $\lambda \in\left[\delta_{k}, \delta_{k+1}\right)$ either $k$ or $k+1$ must be the optimal integer number of classrooms.

3. We now show that in the interval $\lambda \in\left[\delta_{k}, \delta_{k+1}\right)$ there is a critical value of $\lambda$ to the left of which $k$ is the optimal number of classrooms and to the right of which $k+1$ is the optimal number. For $\lambda \in\left[\delta_{k}, \delta_{k+1}\right)$, define:

$$
\widetilde{\Pi}(\lambda) \equiv \widetilde{\pi}(k+1, \lambda)-\widetilde{\pi}(k, \lambda)
$$

Since $k$ is the unique optimal choice of number of classrooms at $\delta_{k}$ in the divisible-classrooms case,

$$
\widetilde{\Pi}\left(\delta_{k}\right)=\widetilde{\pi}\left(k+1, \delta_{k}\right)-\widetilde{\pi}\left(k, \delta_{k}\right)<0
$$


Similarly, since $k+1$ is the unique optimal number of classrooms at $\delta_{k+1}$ in the divisibleclassrooms case,

$$
\widetilde{\Pi}\left(\delta_{k+1}\right)=\widetilde{\pi}\left(k+1, \delta_{k+1}\right)-\widetilde{\pi}\left(k, \delta_{k+1}\right)>0
$$

From (52), we know that $\beta(k)<\beta(k+1)$; the class-size cap starts to bind at a higher value of $\lambda$ for $n=k+1$ than for $n=k$. Using (48), the definition of $\widetilde{\Pi}(\lambda)$ can be restated:

$$
\widetilde{\Pi}(\lambda)=\left\{\begin{array}{lll}
\pi^{*}(k+1, \lambda)-\pi^{*}(k, \lambda) & \text { if } \quad \lambda \leq \beta(k) \\
\pi^{*}(k+1, \lambda)-\pi^{* *}(k, \lambda) & \text { if } \quad \beta(k)<\lambda \leq \beta(k+1) \\
\pi^{* *}(k+1, \lambda)-\pi^{* *}(k, \lambda) & \text { if } \quad \beta(k+1)<\lambda
\end{array}\right.
$$

Note that $\pi^{*}(k, \beta(k))=\pi^{* *}(k, \beta(k))$ and $\pi^{*}(k+1, \beta(k+1))=\pi^{* *}(k+1, \beta(k+1))$. Hence $\widetilde{\Pi}(\lambda)$ is continuous. Now consider the slope of $\widetilde{\Pi}(\lambda)$ against $\lambda$ in each interval:

(a) $\lambda \leq \beta(k)$. The class-size cap binds neither for $n=k$ nor for $n=k+1$.

$$
\frac{\partial^{2} \pi^{*}}{\partial n \partial \lambda}=\frac{\partial}{\partial \lambda}\left(\frac{\partial \pi^{*}}{\partial n}\right)=\frac{\partial}{\partial \lambda}\left(\frac{\partial \mathcal{L}}{\partial n}\right)=\frac{\partial}{\partial \lambda}\left(-F_{c}+\frac{\lambda x^{*} \Theta^{*}}{n}\right)>0
$$

where the second equality follows from (49), the third equality follows from (33b), and the inequality follows from (21b) and (23). Hence:

$$
\frac{\mathrm{d} \widetilde{\Pi}}{\mathrm{d} \lambda}=\frac{\partial \pi^{*}(k+1, \lambda)}{\partial \lambda}-\frac{\partial \pi^{*}(k, \lambda)}{\partial \lambda}>0
$$

(b) $\beta(k)<\lambda \leq \beta(k+1)$. The class-size cap binds for $n=k$ but not for $n=k+1$. Note that

$$
\frac{\partial \pi^{*}}{\partial \lambda}=\frac{\partial \mathcal{L}}{\partial \lambda}=x^{*} \Theta^{*} \ln \left(\frac{n T}{x^{*}}\right)
$$

where $\mathcal{L}$ is given by (42), and the first equality follows by the envelope theorem. Similarly,

$$
\frac{\partial \pi^{* *}}{\partial \lambda}=\frac{\partial \mathcal{L}}{\partial \lambda}=45 n \Theta^{*} \ln \left(\frac{T}{45}\right)
$$

At $n=k$, the optimal enrollment if there were no class-size cap would be greater than or equal to $45 n$; otherwise the cap would not be binding. Hence, comparing (56) and $(57)$

$$
\frac{\partial \pi^{*}(k, \lambda)}{\partial \lambda} \geq \frac{\partial \pi^{* *}(k, \lambda)}{\partial \lambda}
$$

Using step 3a above,

$$
\frac{\partial \pi^{*}(k+1, \lambda)}{\partial \lambda}>\frac{\partial \pi^{*}(k, \lambda)}{\partial \lambda} \geq \frac{\partial \pi^{* *}(k, \lambda)}{\partial \lambda}
$$

Hence:

$$
\frac{\mathrm{d} \widetilde{\Pi}}{\mathrm{d} \lambda}=\frac{\partial \pi^{*}(k+1, \lambda)}{\partial \lambda}-\frac{\partial \pi^{* *}(k, \lambda)}{\partial \lambda}>0
$$

(c) $\beta(k+1)<\lambda$. The class-size cap binds for both $n=k$ and $n=k+1$. Partially 
differentiating (57) and using (51),

$$
\frac{\partial}{\partial n}\left(\frac{\partial \pi^{* *}}{\partial \lambda}\right)=45 \ln \left(\frac{T}{45}\right)\left[\Theta+n \frac{\partial \Theta}{\partial n}\right]>0
$$

Hence

$$
\frac{\mathrm{d} \widetilde{\Pi}}{\mathrm{d} \lambda}=\frac{\partial \pi^{* *}(k+1, \lambda)}{\partial \lambda}-\frac{\partial \pi^{* *}(k, \lambda)}{\partial \lambda}>0
$$

Thus $\widetilde{\Pi}(\lambda)$ is continuous and monotonically increasing in $\lambda$ for all $\lambda \in\left[\delta_{k}, \delta_{k+1}\right)$. Together with the fact that it is negative at $\delta_{k}$ and positive at $\delta_{k+1}$, this implies that there is exactly one critical value, call it $\nu_{k}$, at which $\widetilde{\Pi}\left(\nu_{k}\right)=0$. For $\lambda \in\left[\delta_{k}, \nu_{k}\right), k$ is the optimal integer number of classrooms; for $\lambda \in\left[\nu_{k}, \delta_{k+1}\right), k+1$ is optimal.

4. It remains to consider the regions at the extremes of the support of $\lambda$. Without loss of generality, let $\underline{j}$ be the largest integer such that $\delta_{j} \leq \underline{\lambda}{ }^{46}$ and let $\bar{j}$ be the smallest integer such that $\bar{\lambda} \leq \bar{\delta}_{\bar{j}}$. Within each interval, $\left[\delta_{\underline{j}}, \delta_{\underline{j}+1}\right),\left[\delta_{\underline{j}+1}, \delta_{\underline{j}+2}\right), \ldots,\left[\delta_{\bar{j}-1}, \delta_{\bar{j}}\right)$, the results from steps 1-3 above hold. Truncate the interval $\left(\delta_{\underline{j}}, \delta_{\bar{j}}\right)$ at $\underline{\lambda}$ below and $\bar{\lambda}$ above. If $\nu_{\underline{j}} \leq \underline{\lambda}$, then let $\underline{k}=\underline{j}+1$; else if $\underline{\lambda}<\nu_{\underline{j}}$ then let $\underline{k}=\underline{j}$. If $\nu_{\bar{j}-1}<\bar{\lambda}$, then let $\bar{k}=\bar{j}$; else if $\bar{\lambda} \leq \nu_{\bar{j}-1}$, then let $\bar{k}=\bar{j}-1$. Let $\nu_{\underline{k}-1}=\underline{\lambda}$ and $\nu_{\bar{k}}=\bar{\lambda}$. Then

$$
\nu_{\underline{k}-1}<\nu_{\underline{k}}<\ldots<\nu_{\bar{k}}
$$

form a partition of the set of voucher schools, with the optimal integer number of classrooms equal to $\underline{k}, \underline{k}+1, \ldots, \bar{k}$ between consecutive values, and the lemma is proved.

\section{A.2.4 Discontinuities at Critical Values}

Consider a given $\nu_{k}$ from Lemma 1 , where $\underline{k}<k<\bar{k}$. The fact that $\beta(k+1)>\beta(k)$ (from (52)) implies that it will never be the case that the class-size cap is non-binding to the left of the critical value but binding to the right of it. There are then three cases to consider:

1. The class-size cap is binding neither to the left nor to the right of the critical value: $\nu_{k} \leq$ $\beta(k)<\beta(k+1)$. In this case, $\lim _{\lambda \rightarrow \nu_{k}^{-}} p^{*}, \lim _{\lambda \rightarrow \nu_{k}^{-}} x^{*}$ and $\lim _{\lambda \rightarrow \nu_{k}^{-}} \Theta^{*}$ (the limits as $\lambda$ approaches $\nu_{k}$ from the left) are given by (20a), (20b), and (5) with $n=k \cdot \lim _{\lambda \rightarrow \nu_{k}^{+}} p^{*}$, $\lim _{\lambda \rightarrow \nu_{k}^{+}} x^{*}$ and $\lim _{\lambda \rightarrow \nu_{k}^{+}} \Theta^{*}$ are given by the same expressions with $n=k+1$. The differences in the left and right limits then have the same signs as the partial derivatives of the variables with respect to $n$. By (51), we have immediately that $\frac{\partial p^{*}}{\partial n}>0, \frac{\partial x^{*}}{\partial n}>0$, and $\frac{\partial \Theta^{*}}{\partial n}>0$. Hence:

$$
\begin{aligned}
& \lim _{\lambda \rightarrow \nu_{k}^{-}} p^{*}<\lim _{\lambda \rightarrow \nu_{k}^{+}} p^{*} \\
& \lim _{\lambda \rightarrow \nu_{k}^{-}} x^{*}<\lim _{\lambda \rightarrow \nu_{k}^{+}} x^{*} \\
& \lim _{\lambda \rightarrow \nu_{k}^{-}} \Theta^{*}<\lim _{\lambda \rightarrow \nu_{k}^{+}} \Theta^{*}
\end{aligned}
$$

\footnotetext{
${ }^{46}$ If $\underline{\lambda}<\delta_{1}$ then let $\underline{j}=0$ and $\delta_{0}=0$.
} 
Moreover,

$$
\begin{aligned}
\frac{\partial}{\partial n}\left(\frac{x^{*}}{n}\right) & =\frac{1}{n} \frac{\partial x^{*}}{\partial n}-\frac{x^{*}}{n^{2}} \\
& =\frac{x^{*}}{n^{2}}\left(\frac{\lambda \Psi}{\mu+\lambda \Psi}-1\right)<0
\end{aligned}
$$

and hence:

$$
\lim _{\lambda \rightarrow \nu_{k}^{-}} \frac{x^{*}}{n}>\lim _{\lambda \rightarrow \nu_{k}^{+}} \frac{x^{*}}{n}
$$

2. The class-size cap is binding to the left of the critical value but not to the right: $\beta(k)<$ $\nu_{k}<\beta(k+1)$. It is immediate that,

$$
\lim _{\lambda \rightarrow \nu_{k}^{-}} \frac{x^{*}}{n}=45>\lim _{\lambda \rightarrow \nu_{k}^{+}} \frac{x^{*}}{n}
$$

Consider $x^{*}$ and $\Theta^{*}$ in turn:

(a) If there were no class-size cap, then for $\lambda \in\left(\beta(k), \nu_{k}\right)$, we would have $\frac{\partial x^{*}}{\partial \lambda}>0$. In the presence of the class-size cap, for $\lambda \in\left(\beta(k), \nu_{k}\right)$ we have $\frac{\partial x^{*}}{\partial \lambda}=0$. Hence

$$
\left.\lim _{\lambda \rightarrow \nu_{k}^{-}} x^{*}\right|_{\text {cap }}<\left.\lim _{\lambda \rightarrow \nu_{k}^{-}} x^{*}\right|_{\text {no cap }}
$$

If there were no class-size cap, then by (58b) we would have:

$$
\left.\lim _{\lambda \rightarrow \nu_{k}^{-}} x^{*}\right|_{\text {no cap }}<\lim _{\lambda \rightarrow \nu_{k}^{+}} x^{*}
$$

Hence:

$$
\left.\lim _{\lambda \rightarrow \nu_{k}^{-}} x^{*}\right|_{c a p}<\lim _{\lambda \rightarrow \nu_{k}^{+}} x^{*}
$$

(b) Let $z^{*}=\frac{x^{*}}{n}$. Recalling the assumption that schools cannot price discriminate, the price term can be brought outside the integral in (5) and $\Theta^{*}$ can then be written:

$$
\Theta^{*}=\frac{\int_{\underline{\theta}}^{\bar{\theta}} \theta \frac{1}{\Omega(\theta)}\left(\frac{T}{z^{*}}\right)^{\frac{\theta \lambda}{\mu}} g(\theta) \mathrm{d} \theta}{\int_{\underline{\theta}}^{\bar{\theta}} \frac{1}{\Omega(\theta)}\left(\frac{T}{z^{*}}\right)^{\frac{\theta \lambda}{\mu}} g(\theta) \mathrm{d} \theta}
$$

Note that $\Theta^{*}$ depends only on class size and $\lambda$, not on price, or enrollment or the number of classrooms separately. Differentiating,

$$
\frac{\partial \Theta^{*}}{\partial z}=-\frac{\lambda}{\mu z} \sigma_{\theta \mid \lambda}^{2}<0
$$


Hence (60) implies:

$$
\lim _{\lambda \rightarrow \nu_{k}^{-}} \Theta^{*}<\lim _{\lambda \rightarrow \nu_{k}^{+}} \Theta^{*}
$$

3. If the class-size cap is binding both to the left and to the right of the critical value: $\beta(k)<$ $\beta(k+1) \leq \nu_{k}$. It is immediate that:

$$
\lim _{\lambda \rightarrow \nu_{k}^{-}} z^{*}=\lim _{\lambda \rightarrow \nu_{k}^{+}} z^{*}=45
$$

and:

$$
\lim _{\lambda \rightarrow \nu_{k}^{-}} x^{*}=45 k<45(k+1)=\lim _{\lambda \rightarrow \nu_{k}^{+}} x^{*}
$$

As (61) indicates, $\Theta^{*}$ depends only on class size and $\lambda$. Hence (64) implies:

$$
\lim _{\lambda \rightarrow \nu_{k}^{-}} \Theta^{*}=\lim _{\lambda \rightarrow \nu_{k}^{+}} \Theta^{*}
$$

Since $\frac{\partial \Theta^{*}}{\partial \lambda}>0$ both to the left and to the right of $\nu_{k}$ (refer to (26c)), we have that $\Theta^{*}$ is strictly increasing in $\lambda$ at $\nu_{k}$.

In this case, $p^{*}$ is given by (24a) both to the left and to the right of the critical value. Hence the jump in number of classrooms from $k$ to $k+1$ implies:

$$
\lim _{\lambda \rightarrow \nu_{k}^{-}} p^{*}>\lim _{\lambda \rightarrow \nu_{k}^{+}} p^{*}
$$

To summarize, at $\nu_{k}$, class size is either decreasing or constant in $\lambda$, and enrollment and average willingness to pay are always increasing in $\lambda$. We have no unambiguous result for how price changes with $\lambda$ at $\nu_{k}$. 
Figure 1: Histograms of the number of $4^{\text {th }}$ grades in urban schools, 2002
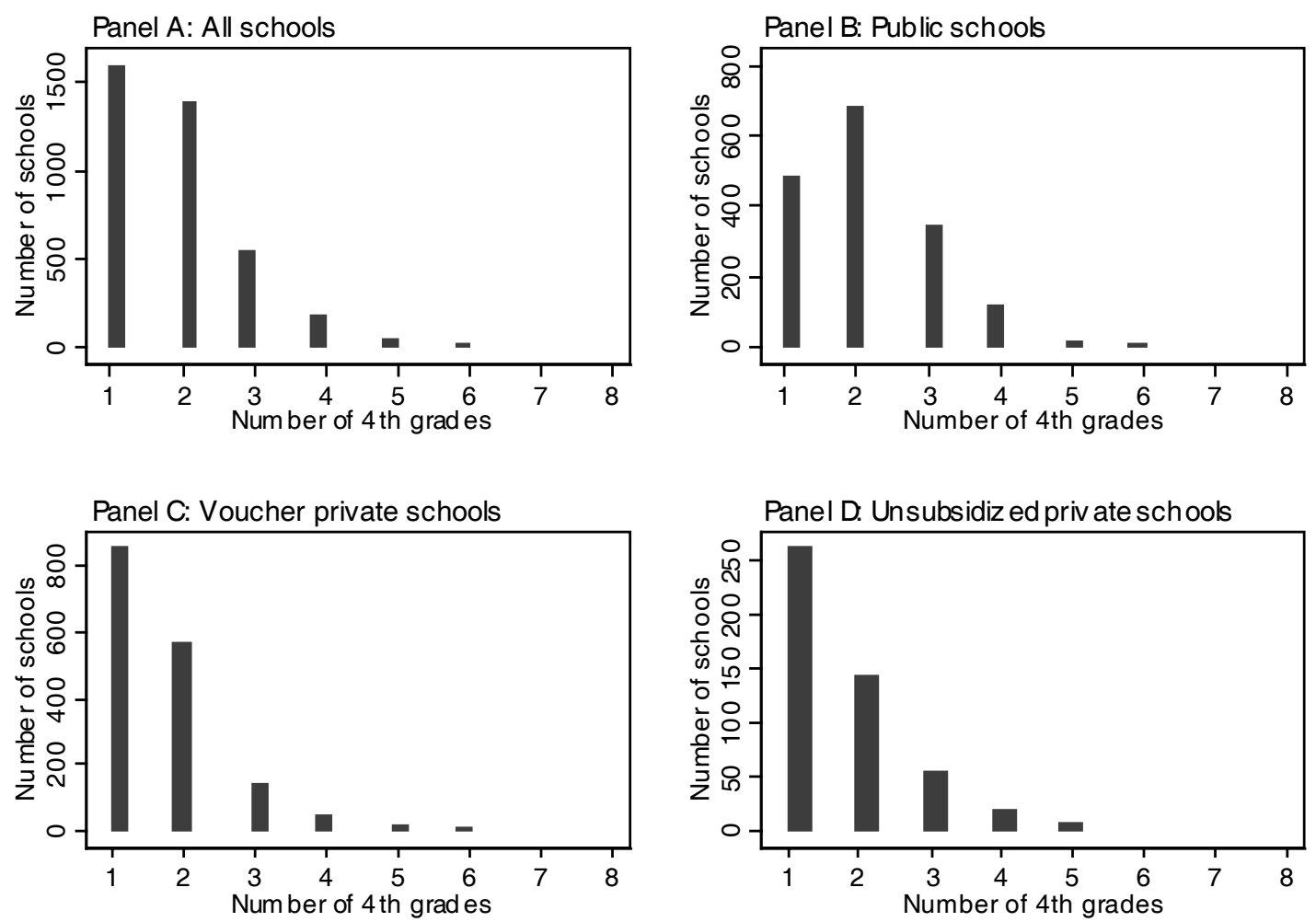

Note: Based on 2002 administrative data for urban schools with positive $4^{\text {th }}$ grade enrollments. The figures cover only schools Chile's Ministry of Education classifies as urban. For voucher schools, panel C excludes about 0.2 percent of schools which report having more than eight $4^{\text {th }}$ grade classes.

Figure 2: Case 1-Divisible classrooms

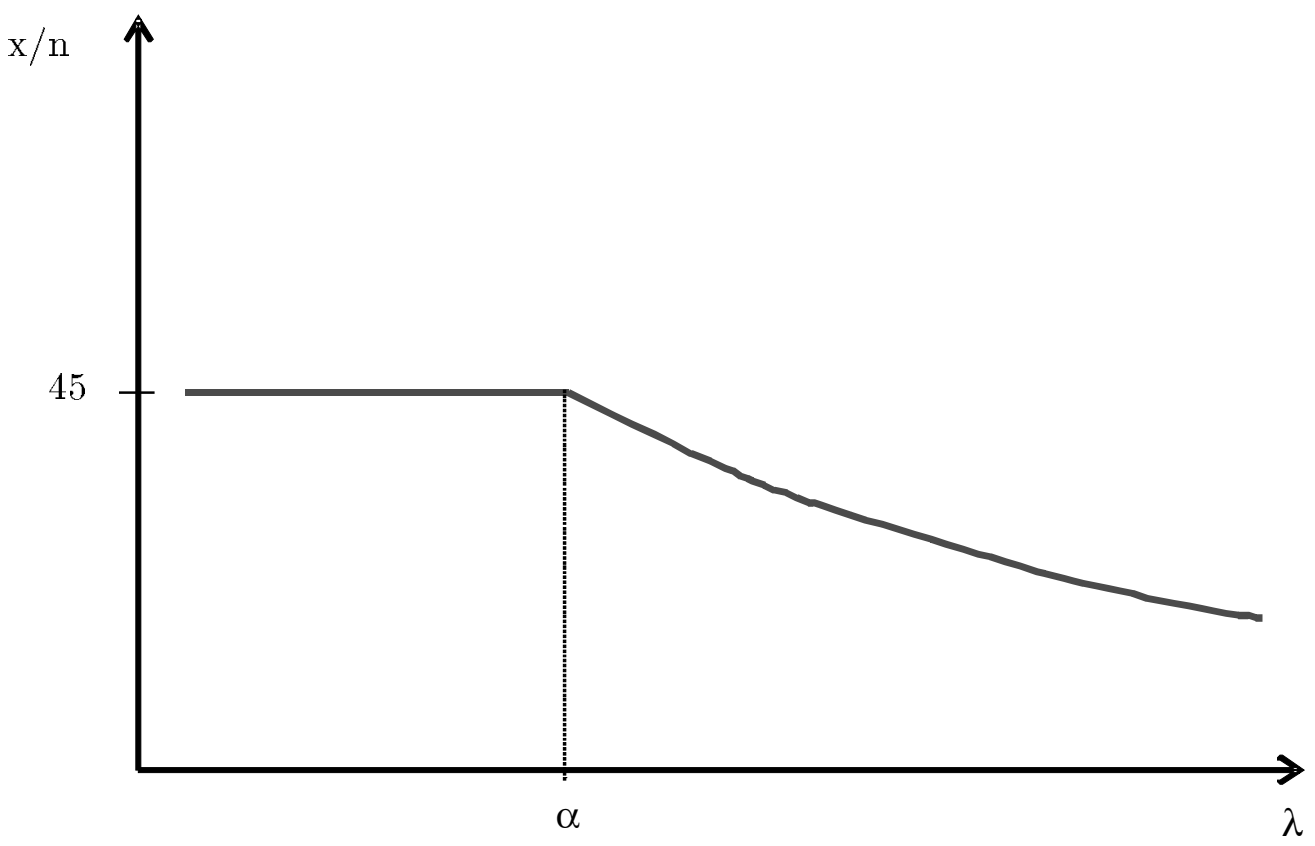


Figure 3: Case 2 - Indivisible classrooms

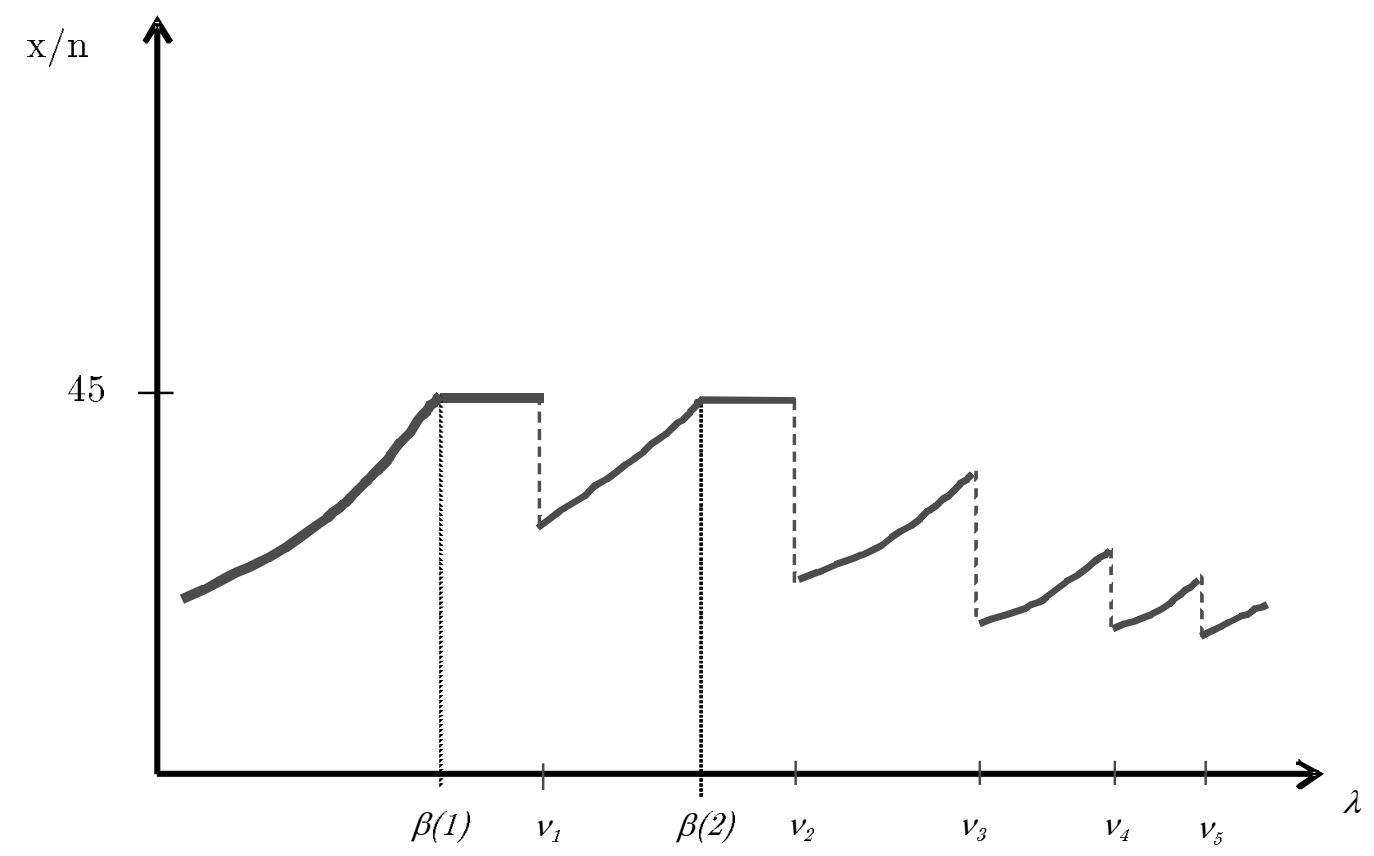


Figure 4: Class size and income/mothers' schooling among urban private voucher schools, 2002
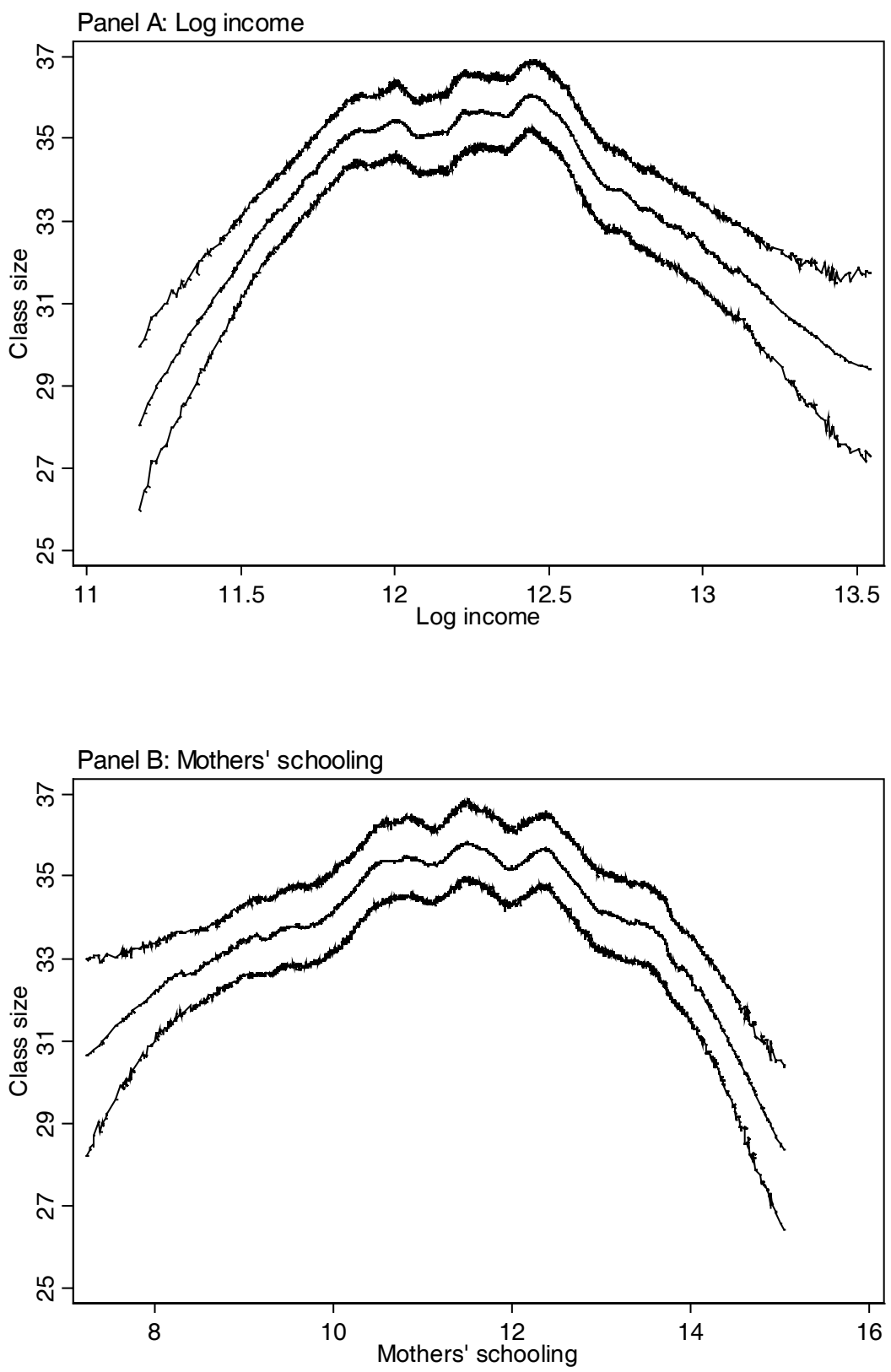

Note: Income and mothers' schooling come from 2002 individual-level SIMCE data aggregated to the school level. Class size is based on 2002 administrative information. In each panel, the lines plot fitted values, along with point-wise confidence intervals, of locally weighted regressions (using Stata's lowess command and a bandwidth of 0.2) of class size on log income (Panel A) and mothers' schooling (Panel B). The figures omit observations below and above the $1^{\text {st }}$ and $99^{\text {th }}$ percentile of income or mothers' schooling. Standard errors are based on a bootstrap procedure with 1,000 replications. We note that the results are very similar if derived using regressions of class size on a $5^{\text {th }}$-order polynomial of the independent variables. 
Figure 5: $4^{\text {th }}$ grade enrollment and class size in urban private voucher schools, 2002

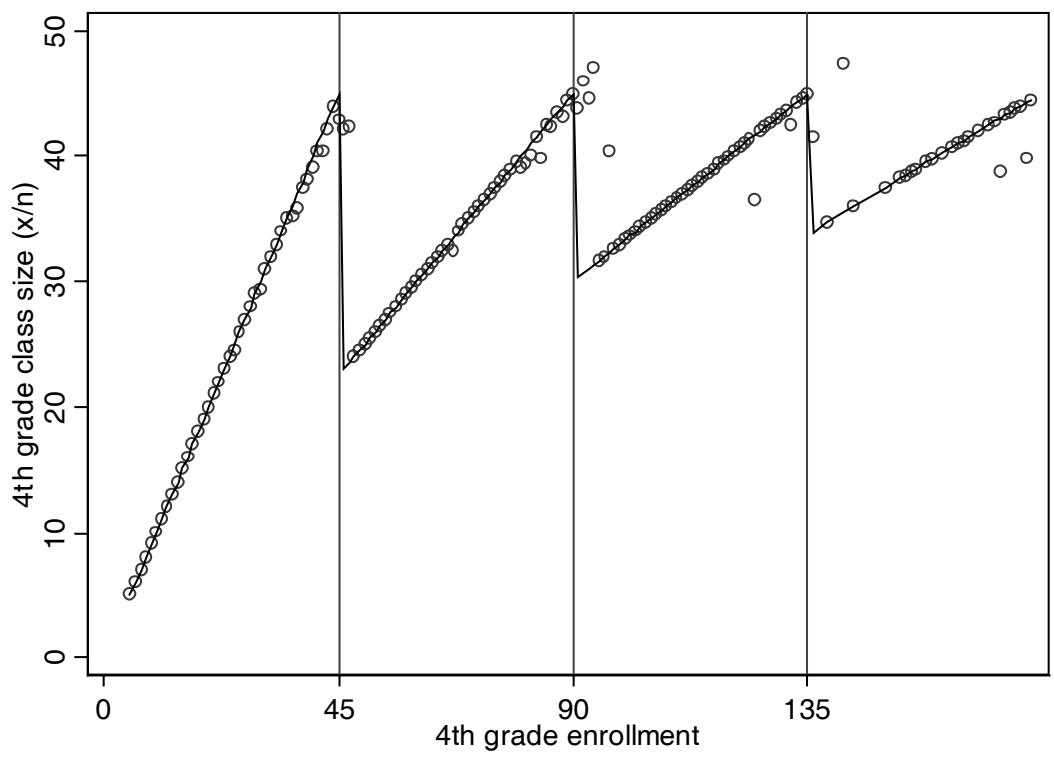

Note: Based on administrative data for 2002. The solid line describes the relationship between enrollment and class size that would exist if the class size rule (equation 30 in the text) were applied mechanically. The circles plot actual enrollment cell means of $4^{\text {th }}$ grade class size. Only data for schools with $4^{\text {th }}$ grade enrollments below 180 are plotted; this excludes less than two percent of all schools.

Figure 6: Test scores and enrollment in urban private voucher schools, 2002
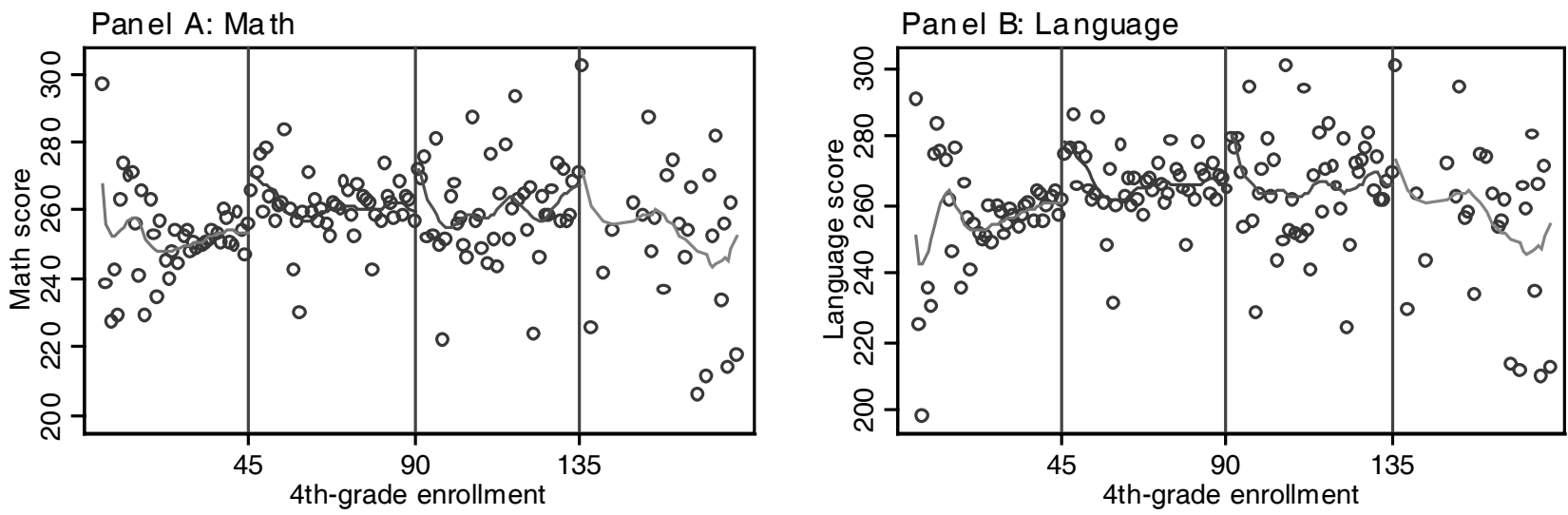

Note: Test scores come from 2002 individual-level SIMCE information aggregated to the school level, and enrollment is drawn from administrative data for the same year. The figures plot "raw" enrollment-cell means of test scores, along with the fitted values of a locally weighted regression calculated within each enrollment segment. 
Figure 7: Histograms of $4^{\text {th }}$ grade enrollment in urban private schools, 2002
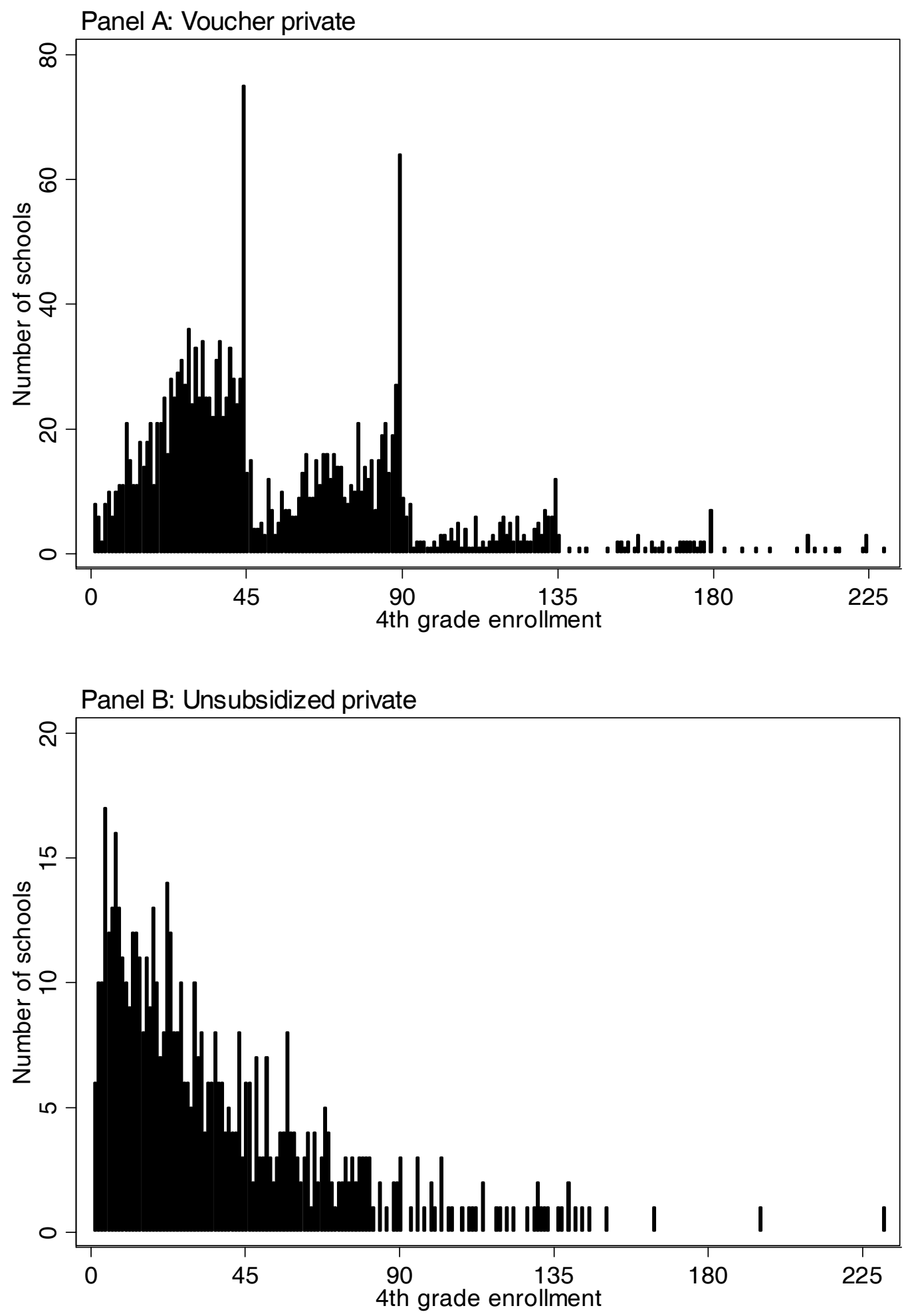

Note: Enrollment is drawn from administrative data for 2002. For visual clarity, only schools with $4^{\text {th }}$ grade enrollments below 225 are displayed. This excludes less than one percent of all schools. 
Figure 8: Student characteristics and enrollment in urban private voucher schools, 2002
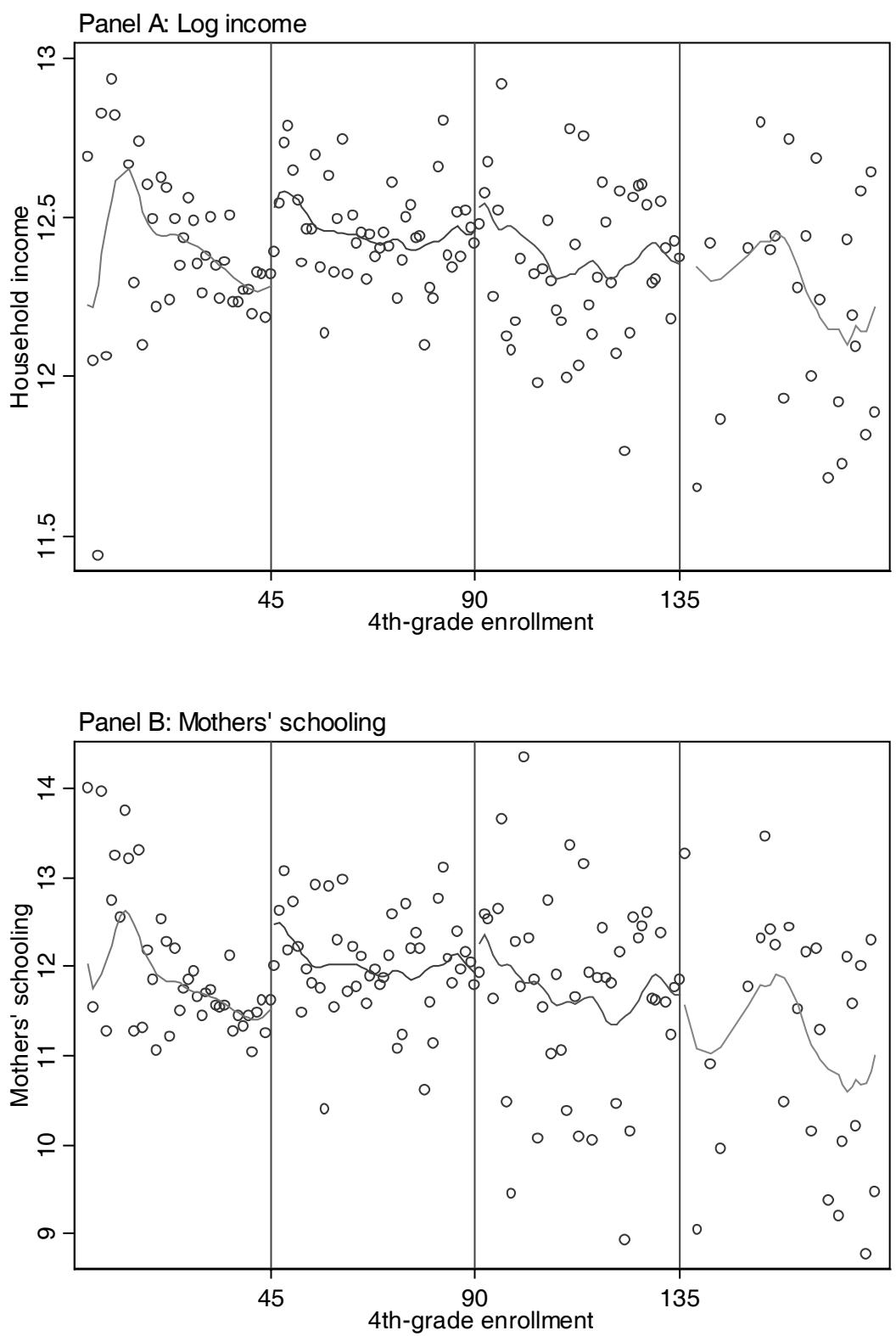

Note: Income and mothers' schooling come from 2002 individual-level SIMCE data aggregated to the school level. Enrollment is drawn from administrative data for the same year. The figure presents "raw" enrollment-cell means, along with the fitted values of a locally weighted regression calculated within each enrollment segment. Only data for schools with $4^{\text {th }}$ grade enrollments below 180 are plotted; this excludes less than two percent of all schools. 
Table 1: Descriptive statistics for urban schools, 2002

\begin{tabular}{|c|c|c|c|c|c|c|c|}
\hline \multirow[t]{2}{*}{ Sample/variable } & \multirow[b]{2}{*}{ Mean } & \multirow[b]{2}{*}{ S.D. } & \multicolumn{5}{|c|}{ Quantile } \\
\hline & & & 10th & 25 th & 50th & 75th & 90th \\
\hline \multicolumn{8}{|l|}{ Panel A: Full sample } \\
\hline Income & 311.2 & 341.7 & 102.5 & 130 & 180 & 303.7 & 781.8 \\
\hline Mothers' schooling & 11.1 & 2.4 & 8.3 & 9.3 & 10.7 & 12.7 & 14.9 \\
\hline Fathers' schooling & 11.3 & 2.5 & 8.5 & 9.4 & 10.8 & 12.9 & 15.2 \\
\hline Math score & 249.3 & 30 & 212.6 & 227.7 & 246.9 & 269.3 & 291.9 \\
\hline Language score & 253.1 & 30.5 & 215.2 & 231.3 & 251.5 & 275.1 & 296 \\
\hline $4^{\text {th }}$ grade class size & 32.9 & 9.2 & 20 & 27 & 34 & 40.3 & 44.3 \\
\hline No. of $4^{\text {th }}$ grade clases & 1.88 & 1.09 & 1 & 1 & 2 & 2 & 3 \\
\hline $4^{\text {th }}$ grade enrollment & 65 & 45.1 & 21 & 33 & 56 & 86 & 122 \\
\hline \multicolumn{8}{|l|}{ Panel B: Public schools } \\
\hline Income & 152.8 & 69.1 & 94.4 & 113.6 & 138.6 & 172.1 & 217 \\
\hline Mothers' schooling & 9.6 & 1.3 & 8.1 & 8.6 & 9.4 & 10.4 & 11.3 \\
\hline Fathers' schooling & 9.7 & 1.4 & 8.1 & 8.8 & 9.6 & 10.6 & 11.5 \\
\hline Math score & 235.1 & 21.4 & 208.7 & 220.6 & 233.8 & 248.8 & 262.2 \\
\hline Language score & 237.9 & 21.6 & 211.2 & 223.9 & 237.5 & 251.8 & 265.8 \\
\hline $4^{\text {th }}$ grade class size & 34.7 & 7.2 & 25 & 30 & 35.5 & 40.3 & 44 \\
\hline No. of $4^{\text {th }}$ grade clases & 2.1 & 1 & 1 & 1 & 2 & 3 & 3 \\
\hline $4^{\text {th }}$ grade enrollment & 75.4 & 42 & 29 & 41.5 & 70 & 98 & 130 \\
\hline \multicolumn{8}{|c|}{ Panel C: Voucher private schools } \\
\hline Income & 250.8 & 142.6 & 115.7 & 155.8 & 213.1 & 307.1 & 428.2 \\
\hline Mothers' schooling & 11.5 & 1.8 & 8.9 & 10.2 & 11.6 & 12.8 & 13.8 \\
\hline Fathers' schooling & 11.5 & 1.9 & 9 & 10.2 & 11.6 & 12.9 & 13.9 \\
\hline Math score & 252.2 & 27.5 & 215.1 & 234.4 & 254.3 & 271.3 & 287.5 \\
\hline Language score & 256.9 & 28.4 & 218.4 & 239.1 & 259.7 & 277.4 & 290.7 \\
\hline $4^{\text {th }}$ grade class size & 34.2 & 9.3 & 21 & 28 & 36 & 42 & 45 \\
\hline No. of $4^{\text {th }}$ grade clases & 1.7 & 1.07 & 1 & 1 & 1 & 2 & 3 \\
\hline $4^{\text {th }}$ grade enrollment & 61.4 & 48.1 & 21 & 31 & 45 & 82.5 & 112 \\
\hline \multicolumn{8}{|c|}{ Panel D: Unsubsidized private schools } \\
\hline Income & 1050.2 & 419.3 & 506.3 & 770.9 & 1003.6 & 1350 & 1673.5 \\
\hline Mothers' schooling & 15.1 & 1.2 & 13.8 & 14.7 & 15.4 & 15.9 & 16.3 \\
\hline Fathers' schooling & 15.6 & 1.3 & 14 & 15 & 15.9 & 16.5 & 16.9 \\
\hline Math score & 288.1 & 25.3 & 254.3 & 276 & 292.9 & 304.7 & 314.1 \\
\hline Language score & 291.8 & 23.7 & 261.8 & 283 & 297.5 & 307 & 315.1 \\
\hline $4^{\text {th }}$ grade class size & 22.4 & 8.6 & 10 & 16.8 & 23 & 28.5 & 34 \\
\hline No. of $4^{\text {th }}$ grade clases & 1.7 & 1 & 1 & 1 & 1 & 2 & 3 \\
\hline $4^{\text {th }}$ grade enrollment & 41.7 & 33.2 & 10 & 17 & 31.5 & 57.5 & 85 \\
\hline
\end{tabular}

Note: Data on monthly income, parental schooling, and test scores come from 2002 individual SIMCE information aggregated to the school level. Income is in thousands of Chilean pesos (the average exchange rate for 2002 was about 700 pesos per U.S. dollar). Class size, the number of classes operated, and enrollment come from administrative data for the same year. The table covers only urban schools. Panel A describes all 3,776 schools in the sample, panel B covers 1,652 public schools, panel C refers to 1,636 voucher private schools, and panel D refers to 488 private unsubsidized institutions. 
Table 2: Class size and income and mothers' schooling among urban private voucher schools, 2002

\begin{tabular}{|c|c|c|c|}
\hline \multirow{3}{*}{ Panel A } & \multicolumn{3}{|c|}{ Dependent var.: 4 th grade class size } \\
\hline & $(1)$ & $(2)$ & $(3)$ \\
\hline & & & \\
\hline \multirow[t]{2}{*}{ Log income } & $120.3^{* * *}$ & $125.5^{* * *}$ & $135.3^{* * *}$ \\
\hline & $(15.2)$ & $(15.6)$ & $(16.7)$ \\
\hline \multirow[t]{2}{*}{$\log$ income $^{2}$} & $-4.9^{* * *}$ & $-5.1^{* * * *}$ & $-5.5^{* * *}$ \\
\hline & $(0.6)$ & $(0.6)$ & $(0.7)$ \\
\hline 13 region dummies & No & Yes & No \\
\hline 318 commune dummies & No & No & Yes \\
\hline $\mathrm{R}^{2}$ & 0.038 & 0.073 & 0.209 \\
\hline $\mathrm{N}$ & 1,636 & 1,636 & 1,636 \\
\hline \multicolumn{4}{|l|}{ Panel B } \\
\hline \multirow[t]{2}{*}{ Mothers' schooling } & $8.5^{* * *}$ & $8.7^{* * *}$ & $9.8^{* * *}$ \\
\hline & $(1.2)$ & $(1.3)$ & $(1.4)$ \\
\hline \multirow[t]{2}{*}{ Mothers' schooling ${ }^{2}$} & $-0.4^{* * *}$ & $-0.4^{* * *}$ & $-0.4^{* * *}$ \\
\hline & $(0.1)$ & $(0.1)$ & $(0.1)$ \\
\hline 13 region dummies & No & Yes & No \\
\hline 318 commune dummies & No & No & Yes \\
\hline $\mathrm{R}^{2}$ & 0.029 & 0.061 & 0.200 \\
\hline $\mathrm{N}$ & 1,636 & 1,636 & 1,636 \\
\hline
\end{tabular}

Note: Income and mothers' schooling are drawn from 2002 individual-level SIMCE data aggregated to the school level. Class size comes from administrative data for the same year. ${ }^{* * * *}$ indicates statistical significance at the $1 \%$ level. 
Table 3: $1^{\text {st }}$ stage, reduced form, and base IV specifications; urban private voucher schools, 2002

\begin{tabular}{|c|c|c|c|c|c|}
\hline & \multirow{2}{*}{$\begin{array}{c}1^{\text {st }} \text { stage } \\
\text { Class } \\
\text { size } \\
(1)\end{array}$} & \multicolumn{2}{|c|}{ Reduced form } & \multicolumn{2}{|c|}{ IV } \\
\hline & & $\begin{array}{l}\text { Math } \\
\text { score } \\
(2) \\
\end{array}$ & $\begin{array}{c}\text { Language } \\
\text { score } \\
(3) \\
\end{array}$ & $\begin{array}{c}\text { Math } \\
\text { score } \\
(4) \\
\end{array}$ & $\begin{array}{c}\text { Language } \\
\text { score } \\
(5) \\
\end{array}$ \\
\hline$\overline{\text { Class size }}$ & & & & $\begin{array}{c}-0.7^{* * *} \\
(0.3)\end{array}$ & $\begin{array}{c}-0.6^{* *} \\
(0.3)\end{array}$ \\
\hline $1\{x \geq 46\}$ & $\begin{array}{c}-16.5^{* * *} \\
(2.7)\end{array}$ & $\begin{array}{c}11.8^{* * * *} \\
(3.2)\end{array}$ & $\begin{array}{l}9.9^{* * *} \\
(3.3)\end{array}$ & & \\
\hline $1\{x \geq 91\}$ & $\begin{array}{l}-4.9^{* *} \\
(2.3)\end{array}$ & $\begin{array}{c}0.0 \\
(4.0)\end{array}$ & $\begin{array}{c}1.6 \\
(4.0)\end{array}$ & & \\
\hline $1\{x \geq 136\}$ & $\begin{array}{l}-4.3^{* *} \\
(2.0)\end{array}$ & $\begin{array}{l}11.5 \\
(13.6)\end{array}$ & $\begin{array}{c}10.9 \\
(12.9)\end{array}$ & & \\
\hline $1\{x \geq 181\}$ & $\begin{array}{l}-3.4 \\
(3.0)\end{array}$ & $\begin{array}{c}11.2 \\
(10.6)\end{array}$ & $\begin{array}{c}11.5 \\
(13.9)\end{array}$ & & \\
\hline$x$ & $\begin{array}{l}0.95^{* * *} \\
(0.01)\end{array}$ & $\begin{array}{c}0.1 \\
(0.1)\end{array}$ & $\begin{array}{l}0.2^{*} \\
(0.1)\end{array}$ & $\begin{array}{l}0.8^{* * * *} \\
(0.2)\end{array}$ & $\begin{array}{l}0.8^{* * *} \\
(0.3)\end{array}$ \\
\hline$(x-46) * 1\{x \geq 46\}$ & $\begin{array}{c}-0.6^{* * *} \\
(0.1)\end{array}$ & $\begin{array}{l}-0.1 \\
(0.2)\end{array}$ & $\begin{array}{l}-0.2 \\
(0.2)\end{array}$ & $\begin{array}{l}-0.6^{* *} \\
(0.3)\end{array}$ & $\begin{array}{l}-0.6^{* * *} \\
(0.3)\end{array}$ \\
\hline$(x-91) * 1\{x \geq 91\}$ & $\begin{array}{l}-0.3^{* *} \\
(0.1)\end{array}$ & $\begin{array}{c}0.0 \\
(0.1)\end{array}$ & $\begin{array}{l}-0.1 \\
(0.1)\end{array}$ & $\begin{array}{l}-0.2^{*} \\
(0.1)\end{array}$ & $\begin{array}{l}-0.3^{* * *} \\
(0.1)\end{array}$ \\
\hline$(x-136) * 1\{x \geq 136\}$ & $\begin{array}{c}0.0 \\
(0.1)\end{array}$ & $\begin{array}{l}-0.6 \\
(0.4)\end{array}$ & $\begin{array}{l}-0.4 \\
(0.4)\end{array}$ & $\begin{array}{l}-0.2 \\
(0.2)\end{array}$ & $\begin{array}{l}-0.1 \\
(0.2)\end{array}$ \\
\hline$(x-181) * 1\{x \geq 181\}$ & $\begin{array}{l}-0.1 \\
(0.1)\end{array}$ & $\begin{array}{c}0.2 \\
(0.5)\end{array}$ & $\begin{array}{c}0.2 \\
(0.6)\end{array}$ & $\begin{array}{c}0.1 \\
(0.3)\end{array}$ & $\begin{array}{c}0.1 \\
(0.4)\end{array}$ \\
\hline $\begin{array}{l}\mathrm{N} \\
\mathrm{R}^{2}\end{array}$ & $\begin{array}{l}1,623 \\
0.844\end{array}$ & $\begin{array}{l}1,623 \\
0.069\end{array}$ & $\begin{array}{l}1,623 \\
0.072\end{array}$ & 1,623 & 1,623 \\
\hline
\end{tabular}

Note: Test scores are based on 2002 SIMCE individual-level data, aggregated to the school level. Class size and enrollment come from administrative information for the same year. ${ }^{* * *}$ indicates statistical significance at the $1 \%$ level; ${ }^{* * *}$ at $5 \%$, and ${ }^{*}$ at $10 \%$. All regressions are clustered by enrollment levels; see Lee and Card (forthcoming). The table focuses only on effects around the first four cut-offs, excluding the less than one percent of schools that report $4^{\text {th }}$ grade enrollments in excess of 225 students. 
Table 4: Within-enrollment band IV regressions; urban private voucher schools, 2002

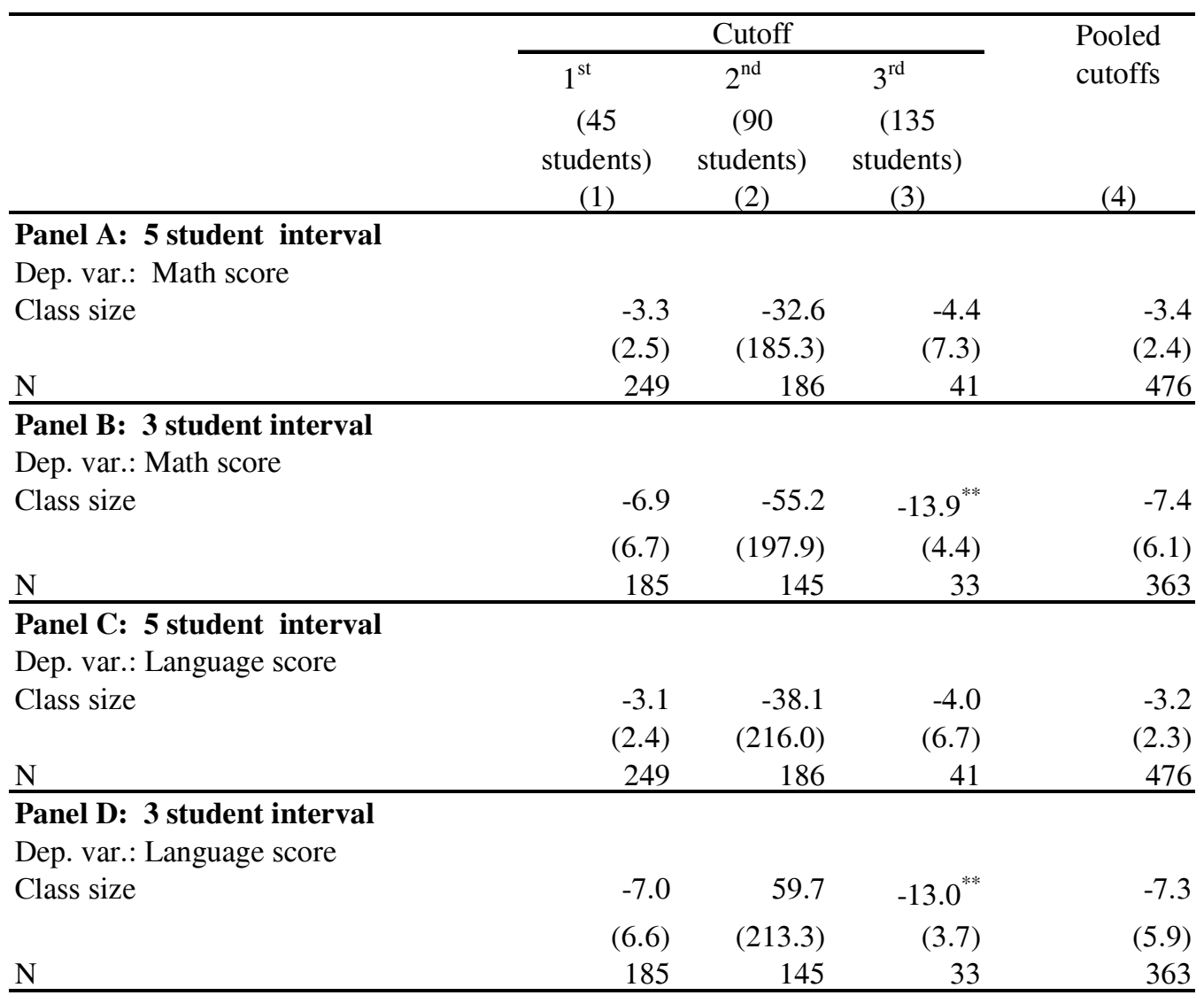

Notes: Test scores are from 2002 SIMCE individual-level data, aggregated to the school level. Class size and enrollment come from administrative information for the same year. Columns present regressions within 5 (panels A and C) and 3 (panels B and D) student enrollment bands around the first three cut-offs. Separate results around the fourth cut-off are omitted for the sake of space; they account for less than 1 percent of observations. Columns 1-3 are IV specifications using an indicator for whether schools' enrollment is above the respective cut-off as an instrument. As van der Klaauw (2002) indicates, these are equivalent to simple Wald estimates of the effect of class size around each discontinuity. Column 4 produces similar estimates pooling all three local samples and using the three cut-offs $(1\{x>45\}, 1\{x>90\}$, and $1\{x>135\})$ as instruments. All regressions are clustered around enrollment levels, see Lee and Card (forthcoming). 
Table 5: Behavior of selected variables around enrollment cut-offs and IV specifications; urban private voucher schools, 2002

\begin{tabular}{|c|c|c|c|c|c|}
\hline & \multirow{2}{*}{$\begin{array}{l}\text { Mothers' } \\
\text { schooling } \\
\text { (1) }\end{array}$} & \multirow{2}{*}{$\begin{array}{l}\text { Fathers' } \\
\text { schooling } \\
(2)\end{array}$} & \multirow{2}{*}{$\begin{array}{l}\text { Household } \\
\text { income } \\
\text { (3) } \\
\end{array}$} & \multicolumn{2}{|c|}{ IV } \\
\hline & & & & $\begin{array}{l}\text { Math } \\
\text { (4) }\end{array}$ & $\begin{array}{c}\text { Language } \\
(5)\end{array}$ \\
\hline Class size & & & & $\begin{array}{r}-0.1 \\
(0.1)\end{array}$ & $\begin{array}{r}0.1 \\
(0.1)\end{array}$ \\
\hline $1\{x \geq 46\}$ & $\begin{array}{r}0.93^{* * * *} \\
(0.2)\end{array}$ & $\begin{array}{r}0.94^{* * * *} \\
(0.2)\end{array}$ & $\begin{array}{c}66.6^{* * *} \\
(14.1)\end{array}$ & & \\
\hline $1\{x \geq 91\}$ & $\begin{array}{r}0.03 \\
(0.2)\end{array}$ & $\begin{array}{r}0.03 \\
(0.2)\end{array}$ & $\begin{array}{r}17.6 \\
(17.3)\end{array}$ & & \\
\hline $1\{x \geq 136\}$ & $\begin{array}{l}0.66 \\
(0.7)\end{array}$ & $\begin{array}{l}0.86 \\
(0.8)\end{array}$ & $\begin{array}{l}143.7^{*} \\
(79.4)\end{array}$ & & \\
\hline $1\{x \geq 181\}$ & $\begin{array}{c}0.66 \\
(1.1)\end{array}$ & $\begin{array}{c}0.71 \\
(1.1)\end{array}$ & $\begin{array}{r}53.1 \\
(77.7)\end{array}$ & & \\
\hline$x$ & $\begin{array}{r}-0.02^{*} \\
(0.0)\end{array}$ & $\begin{array}{r}-0.02^{*} \\
(0.0)\end{array}$ & $\begin{array}{c}-2.4^{\text {****** }} \\
(0.8)\end{array}$ & $\begin{array}{c}0.4^{* * * *} \\
(0.1)\end{array}$ & $\begin{array}{c}0.4^{\text {*** }} \\
(0.1)\end{array}$ \\
\hline$(x-46) * 1\{x \geq 46\}$ & $\begin{array}{l}0.02^{*} \\
(0.0)\end{array}$ & $\begin{array}{l}0.01 \\
(0.0)\end{array}$ & $\begin{array}{c}2.3^{* * * *} \\
(0.8)\end{array}$ & $\begin{array}{r}-0.4^{* * * *} \\
(0.1)\end{array}$ & $\begin{array}{r}-0.4^{* * * *} \\
(0.1)\end{array}$ \\
\hline$(x-91) * 1\{x \geq 91\}$ & $\begin{array}{l}-0.01 \\
(0.0)\end{array}$ & $\begin{array}{l}0.00 \\
(0.0)\end{array}$ & $\begin{array}{l}-0.7 \\
(0.6)\end{array}$ & $\begin{array}{r}0.1 \\
(0.1)\end{array}$ & $\begin{array}{r}0 \\
(0.1)\end{array}$ \\
\hline$(x-136) * 1\{x \geq 136\}$ & $\begin{array}{c}-0.02 \\
(0.0)\end{array}$ & $\begin{array}{r}-0.03 \\
(0.0)\end{array}$ & $\begin{array}{l}-3.5 \\
(2.3)\end{array}$ & $\begin{array}{c}-0.2^{* * *} \\
(0.1)\end{array}$ & $\begin{array}{l}-0.1 \\
(0.1)\end{array}$ \\
\hline$(x-181)^{*} 1\{x \geq 181\}$ & $\begin{array}{l}0.01 \\
(0.0)\end{array}$ & $\begin{array}{l}0.02 \\
(0.0)\end{array}$ & $\begin{array}{r}4 \\
(3.4)\end{array}$ & $\begin{array}{r}0.1 \\
(0.1)\end{array}$ & $\begin{array}{r}0.1 \\
(0.2)\end{array}$ \\
\hline Mothers' schooling & & & & $\begin{array}{c}8.5^{* * *} \\
(0.9)\end{array}$ & $\begin{array}{r}9.5^{* * *} \\
(1.0)\end{array}$ \\
\hline Fathers' schooling & & & & $\begin{array}{c}1.6^{*} \\
(0.9)\end{array}$ & $\begin{array}{r}1.1 \\
(0.9)\end{array}$ \\
\hline Household income & & & & $\begin{array}{r}13.4^{* * *} \\
(5.4)\end{array}$ & $\begin{array}{r}16.6^{* * * *} \\
(5.5)\end{array}$ \\
\hline $\mathrm{N}$ & 1,623 & 1,623 & 1,623 & 1,623 & 1,623 \\
\hline $\mathrm{R}^{2}$ & 0.034 & 0.032 & 0.029 & & \\
\hline
\end{tabular}

Notes: Test scores and socioeconomic status measures are from 2002 SIMCE individual-level data, aggregated to the school level. Class size and enrollment come from administrative information for the same year. ${ }^{* * *}$ indicates statistical significance at $1 \%$ level; ${ }^{* *}$ at $5 \%$, and ${ }^{*}$ at $10 \%$. All regressions are clustered by enrollment levels. The table focuses only on effects around the first four cut-offs, excluding the less than one percent of schools that report $4^{\text {th }}$ grade enrollments in excess of 225 . 
Table 6: Reduced form regressions with piecewise control functions of higher order

\begin{tabular}{|c|c|c|c|c|}
\hline & \multicolumn{4}{|c|}{ Specification of the piecewise control function } \\
\hline & $\begin{array}{c}1 \mathrm{st} \\
\text { order } \\
(1)\end{array}$ & $\begin{array}{l}\text { 2nd } \\
\text { order } \\
(2) \\
\end{array}$ & $\begin{array}{c}\text { 3rd } \\
\text { order } \\
(3)\end{array}$ & $\begin{array}{l}\text { 4th } \\
\text { order } \\
(4)\end{array}$ \\
\hline \multicolumn{5}{|c|}{ Panel A-Dep. var.: Class size } \\
\hline $1\{x \geq 46\}$ & $\begin{array}{c}-16.5^{* * * *} \\
(2.7)\end{array}$ & $\begin{array}{c}-10.0^{* * *} \\
(4.1)\end{array}$ & $\begin{array}{c}0.6 \\
(3.2)\end{array}$ & $\begin{array}{c}1.5 \\
(3.1)\end{array}$ \\
\hline $1\{x \geq 91\}$ & $\begin{array}{c}-4.9^{* *} \\
(2.3)\end{array}$ & $\begin{array}{c}-2.4 \\
(1.6)\end{array}$ & $\begin{array}{l}4.9^{* *} \\
(2.2)\end{array}$ & $\begin{array}{c}3.3 \\
(2.1) \\
\end{array}$ \\
\hline \multicolumn{5}{|c|}{ Panel B-Dep. var.: Math score } \\
\hline $1\{x \geq 46\}$ & $\begin{array}{c}11.8^{* * * *} \\
(3.2)\end{array}$ & $\begin{array}{c}11.5^{* * *} \\
(3.8)\end{array}$ & $\begin{array}{c}24.7^{* * * *} \\
(4.8)\end{array}$ & $\begin{array}{c}22.3^{* * *} \\
(4.7)\end{array}$ \\
\hline $1\{x \geq 91\}$ & $\begin{array}{c}-0.0 \\
(4.0)\end{array}$ & $\begin{array}{l}6.6^{* *} \\
(3.3)\end{array}$ & $\begin{array}{c}15.5^{* * *} \\
(2.8)\end{array}$ & $\begin{array}{c}19.8^{* * *} \\
(4.0)\end{array}$ \\
\hline \multicolumn{5}{|c|}{ Panel C-Dep. var.: Language score } \\
\hline $1\{x \geq 46\}$ & $\begin{array}{c}9.9^{* * * *} \\
(3.3)\end{array}$ & $\begin{array}{c}10.9^{* * *} \\
(3.9)\end{array}$ & $\begin{array}{c}24.2^{* * * *} \\
(3.9)\end{array}$ & $\begin{array}{c}24.2^{* * *} \\
(4.0)\end{array}$ \\
\hline $1\{x \geq 91\}$ & $\begin{array}{c}1.6 \\
(4.0) \\
\end{array}$ & $\begin{array}{l}7.4^{* *} \\
(3.2) \\
\end{array}$ & $\begin{array}{c}19.6^{* * * *} \\
(2.9) \\
\end{array}$ & $\begin{array}{c}18.6^{* * * *} \\
(3.4) \\
\end{array}$ \\
\hline \multicolumn{5}{|c|}{ Panel D-Dep. var.: Mothers' schooling } \\
\hline $1\{x \geq 46\}$ & $\begin{array}{c}0.93^{* * *} \\
(0.20)\end{array}$ & $\begin{array}{c}0.91^{* * *} \\
(0.22)\end{array}$ & $\begin{array}{l}1.21^{* * *} \\
(0.24)\end{array}$ & $\begin{array}{l}1.11^{* * *} \\
(0.24)\end{array}$ \\
\hline $1\{x \geq 91\}$ & $\begin{array}{c}0.03 \\
(0.22) \\
\end{array}$ & $\begin{array}{c}0.29 \\
(0.26) \\
\end{array}$ & $\begin{array}{c}0.55 \\
(0.35) \\
\end{array}$ & $\begin{array}{c}0.40 \\
(0.40) \\
\end{array}$ \\
\hline \multicolumn{5}{|c|}{ Panel E-Dep. var.: Fathers' schooling } \\
\hline $1\{x \geq 46\}$ & $\begin{array}{l}0.94^{* * * *} \\
(0.20)\end{array}$ & $\begin{array}{l}0.93^{* * * *} \\
(0.24)\end{array}$ & $\begin{array}{l}1.14^{* * * *} \\
(0.29)\end{array}$ & $\begin{array}{l}1.05^{\text {**** }} \\
(0.28)\end{array}$ \\
\hline $1\{x \geq 91\}$ & $\begin{array}{c}0.03 \\
(0.22)\end{array}$ & $\begin{array}{c}0.25 \\
(0.26)\end{array}$ & $\begin{array}{c}0.61^{*} \\
(0.36)\end{array}$ & $\begin{array}{c}0.47 \\
(0.41)\end{array}$ \\
\hline \multicolumn{5}{|c|}{ Panel F-Dep. var.: Household income } \\
\hline $1\{x \geq 46\}$ & $\begin{array}{l}66.6^{* * *} \\
(14.1)\end{array}$ & $\begin{array}{l}76.1^{* * *} \\
(14.5)\end{array}$ & $\begin{array}{l}69.5^{* * *} \\
(17.4)\end{array}$ & $\begin{array}{l}68.4^{* * *} \\
(19.0)\end{array}$ \\
\hline $1\{x \geq 91\}$ & $\begin{array}{c}17.6 \\
(17.3) \\
\end{array}$ & $\begin{array}{r}29.6 \\
(20.1) \\
\end{array}$ & $\begin{array}{c}40.5 \\
(27.6) \\
\end{array}$ & $\begin{array}{c}22.3 \\
(31.1) \\
\end{array}$ \\
\hline $\mathrm{N}$ & 1,623 & 1,623 & 1,623 & 1,623 \\
\hline
\end{tabular}

Note: Test scores and socioeconomic status measures are from 2002 SIMCE individual-level data, aggregated to the school level. Class size and enrollment come from administrative information for the same year. ${ }^{* * *}$ indicates statistical significance at $1 \%$ level; ${ }^{* *}$ at $5 \%$, and ${ }^{*}$ at $10 \%$. All regressions are clustered by enrollment levels. This table analyzes the robustness of reduced form results to the inclusion of higher order piecewise control functions (Van der Klaauw, 2002). The results in column 1 (panels A-C) replicate those in Table 3 above (columns 1-3). The results in column 1 (panels D-F) replicate those in Table 5 above (columns 1-3). The remaining columns then explore how these results change as higher order piecewise control functions are added. For the sake of space, these panels report only the coefficients on the first two cut-offs, which correspond to the majority of observations. 